\title{
Mobile Working Hydraulic System Dynamics
}

\author{
Mikael Axin
}

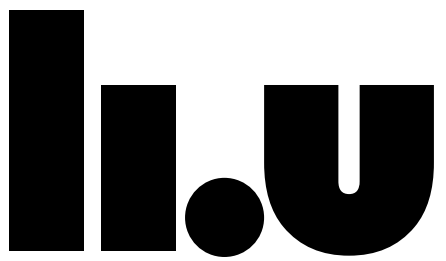

LINKÖPING UNIVERSITY

Division of Fluid and Mechatronic Systems

Department of Management and Engineering

Linköping University, SE-581 83 Linköping, Sweden 
Copyright @ Mikael Axin, 2015

Mobile Working Hydraulic System Dynamics

ISBN 978-91-7685-971-1

ISSN 0345-7524

Distributed by:

Division of Fluid and Mechatronic Systems

Department of Management and Engineering

Linköping University

SE-581 83 Linköping, Sweden

Printed in Sweden by LiU-Tryck, Linköping, 2015. 
To Elsa

Barn tänker inte på den tid som gått eller den tid som kommer. De njuter ögonblicket, vilket få av oss gör.

Jean de La Bruyère (1645-1696) 
Det viktigaste en far kan göra för sina barn är att älska deras mor.

David O. McKay (1873-1970) 


\section{Abstract}

This thesis deals with innovative working hydraulic systems for mobile machines. Flow control systems are studied as an alternative to load sensing. The fundamental difference is that the pump is controlled based on the operator's command signals rather than feedback signals from the loads. This control approach enables higher energy efficiency and there is no load pressure feedback causing stability issues. Experimental results show a reduced pump pressure margin and energy saving potential for a wheel loader application.

The damping contribution from the inlet and outlet orifice in directional valves is studied. Design rules are developed and verified by experiments.

A novel system architecture is proposed where flow control, load sensing and open-centre are merged into a generalized system description. The proposed system is configurable and the operator can realize the characteristics of any of the standard systems without compromising energy efficiency. This can be done non-discretely on-the-fly. Experiments show that it is possible to avoid unnecessary energy losses while improving system response and increasing stability margins compared to load sensing. Static and dynamic differences between different control modes are also demonstrated experimentally. 


\section{Populärvetenskaplig sammanfattning}

\section{Arbetshydraulik i mobila maskiner}

Hydrauliska system används i en mängd olika mobila tillämpningar, såsom entreprenad-, skogs- och jordbruksmaskiner. Hydraulik kan användas för både framdrivningen och arbetshydrauliken. Ett exempel på arbetshydraulik är det system som styr skoprörelsen hos en grävmaskin. Forskningen som presenteras i den här doktorsavhandlingen behandlar arbetshydrauliksystem i mobila maskiner. Innovativa systemkonstruktioner föreslås och diskuteras i relation till både befintliga och ännu inte kommersiellt tillgängliga system för arbetshydraulik.

Idag styrs hydrauliken hos de flesta mobila maskiner med öppetcentrum system. I maskiner med höga krav på energieffektivitet används vanligtvis lastkännande system. I den här avhandlingen studeras flödesstyrda system som ett alternativ till lastkännande system. Den huvudsakliga skillnaden är hur systemets pump styrs. I ett lastkännande system styrs pumpens tryck genom att den "känner" lasten. I ett flödesstyrt system skickar pumpen istället ut den mängd flöde som operatören begär. Detta gör att energieffektiviteten blir högre i flödesstyrda system eftersom tryckdifferensen mellan pump och last ges av systemets motstånd snarare än en förinställd konstant tryckskillnad. Detta bekräftas genom mätningar på en hjullastare. Under en typisk arbetscykel minskas energiåtgången för arbetshydrauliken med cirka $15 \%$. Flödesstyrda system skulle kunna vara ett alternativ till lastkännande system i framtiden.

På grund av maskinernas mångsidighet har olika typer av hydraulsystem utvecklats för olika tillämpningar. Viktiga egenskaper för ett hy- 
draulsystem är bland annat energieffektivitet, styrbarhet, dämpning och komplexitet. I den här doktorsavhandlingen presenteras ett flexibelt hydraulsystem där operatören har möjlighet att ändra styregenskaper. Det är möjligt att realisera ett lastkännande system, ett flödesstyrt system, ett öppet-centrum system och en blandning däremellan, utan att kompromissa med energieffektiviteten. Mätningar på en lastbilskran demonstrerar systemets prestanda. Detta flexibla hydraulsystem skulle kunna vara ett alternativ i framtiden för att undvika några av de kompromisser som annars måste göras. 


\section{Acknowledgements}

The work presented in this thesis has been carried out at the Division of Fluid and Mechatronic Systems (Flumes) at Linköping University. There are several people who have made this thesis possible and to whom I would like to express my gratitude.

First of all I would like to thank my supervisor, Professor Petter Krus, for his support, supervision and valuable input to my work. I am also very grateful to Professor Jan-Ove Palmberg, former head of division. Thank you for giving me the opportunity to be a part of this division. I would like to give special thanks to Doctor Björn Eriksson, co-author of most of my papers, for his great support and commitment during the course of my work. To my other colleagues, thank you for making the university a fun place to work at.

Thanks go to Parker Hannifin for their financial involvement and their help with hardware and other resources. A special thank you to Erik Forsberg; even on vacation I can count on your support.

Most of all, I would like to thank my family and friends for always being there for me. Christer and Gunnel, I realize how lucky I am to have you as father and mother. Johan, Per, and many more, thank you for all the fun adventures and trips. I hope for many more in the future. My greatest gratitude goes to my wife Jennie and our wonderful daughter Elsa for their great support, encouragement and love.

Linköping, August, 2015

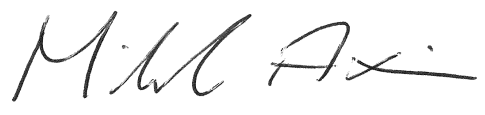

Mikael Axin 


\section{Papers}

The following six appended papers will be referred to by their Roman numerals. All papers are printed in their originally published state with the exception of minor errata and changes in text and figure layout in order to maintain consistency throughout the thesis.

In all papers, the first author is the main author, responsible for the work presented, with additional support from the co-writers. A short summary of each paper can be found in chapter 11.

[I] M. Axin, B. Eriksson, and P. Krus. "Flow versus pressure control of pumps in mobile hydraulic systems". In: Proceedings of the Institution of Mechanical Engineers, Part I: Journal of Systems and Control Engineering. 228(4) (2014), pp. 245-256.

[II] M. Axin, B. Eriksson, J.-O. Palmberg, and P. Krus. "Dynamic Analysis of Single Pump, Flow Controlled Mobile Systems". In: The Twelfth Scandinavian International Conference on Fluid Power (SICFP'11). Vol. 2. Tampere, Finland, 18-20 May 2011, pp. 223-238.

[III] M. Axin, J.-O. Palmberg, and P. Krus. "Optimized Damping in Cylinder Drives Using the Meter-out Orifice - Design and Experimental Verification". In: 8th International Fluid Power Conference (IFK). Vol. 1. Dresden, Germany, 26-28 March 2012, pp. $579-591$.

[IV] M. Axin, B. Eriksson, and P. Krus. "A Hybrid of Pressure and Flow Control in Mobile Hydraulic Systems". In: 9th International Fluid Power Conference (IFK). Vol. 1. Aachen, Germany, 24-26 March 2014, pp. 190-201. 
[V] M. Axin, B. Eriksson, and P. Krus. "Energy Efficient Fluid Power System for Mobile Machines with Open-centre Characteristics". In: 9th JFPS International Symposium on Fluid Power. Matsue, Japan, 28-31 October 2014, pp. 452-459.

[VI] M. Axin, B. Eriksson, and P. Krus. "A Flexible Working Hydraulic System for Mobile Machines". Submitted to: International Journal of Fluid Power, 2015.

\section{Other papers and publications}

The following six publications are not included in the thesis but constitutes an important part of the background. The first author is the main author, responsible for the work presented. An exception is paper [VIII], where the two first authors are the main authors, responsible for the work presented, with additional support from the co-writers.

[VII] M. Axin, B. Eriksson, and J.-O. Palmberg. "Energy Efficient Load Adapting System Without Load Sensing - Design and Evaluation". In: The 11th Scandinavian International Conference on Fluid Power (SICFP'09). Linköping, Sweden, 2-4 June 2009.

[VIII] M. Axin, R. Braun, A. Dell'Amico, B. Eriksson, P. Nordin, K. Pettersson, I. Staack, and P. Krus. "Next Generation Simulation Software using Transmission Line Elements". In: Fluid Power and Motion Control (FPMC). Bath, UK, 15-17 September 2010, pp. 265-276.

[IX] M. Axin. "Ökad dämpning genom rätt design av utloppsstrypningen". In: Hydraulikdagarna. Linköping, Sweden, 17-18 April 2012 (in Swedish).

[X] M. Axin. "Fluid Power Systems for Mobile Applications - with a Focus on Energy Efficiency and Dynamic Characteristics". Licentiate thesis. Linköping University, 2013.

[XI] M. Axin and P. Krus. "Design Rules for High Damping in Mobile Hydraulic Systems". In: The 13th Scandinavian International Conference on Fluid Power (SICFP2013). Linköping, Sweden, 3-5 June 2013. 
[XII] M. Axin. "Arbetshydraulik i mobila maskiner". In: Hydraulikdagarna. Linköping, Sweden, 16-17 March 2015 (in Swedish). 


\section{Contents}

1 Introduction 1

1.1 Background . . . . . . . . . . . . . . . 1

1.2 Aims . . . . . . . . . . . . . . 2

1.3 Delimitations . . . . . . . . . . . . . . 2

1.4 Contribution ................ 3

1.5 Research Method . . . . . . . . . . . . . . 3

1.6 Thesis Outline . . . . . . . . . . . . . . 4

2 Mobile Working Hydraulic Systems 5

2.1 Valve Controlled Systems _. . . . . . . . . . . . 6

2.2 Valveless Systems . . . . . . . . . . . . . . . . . . . . . 9

2.3 System Summary . . . . . . . . . . . . . . . . . . 10

2.4 Single Pump Systems using Conventional Spool Valves . . 10

2.4 .1 Open-centre . . . . . . . . . . . . . . 10

2.4 .2 Load Sensing . . . . . . . . . . . . . . . 12

2.4.3 Open-centre Load Sensing . . . . . . . . . . . . 13

2.4.4 Negative Load Sensing . . . . . . . . . . . . . . . . 14

2.4.5 Negative Flow Control . . . . . . . . . . . . . . 15

2.4 .6 Positive Flow Control . . . . . . . . . . . . . 16

2.4 .7 Flow Control . . . . . . . . . . . . . . . 17

3 Flow Control Concepts 19

3.1 Pressure Compensators . . . . . . . . . . . . . . 21

3.1.1 Traditional Compensators . . . . . . . . . . . . 21

3.1.2 Flow Sharing Compensators . . . . . . . . . . . . 23

3.2 Pump and Valve Control Approaches . . . . . . . . . . . 24

3.2.1 Flow Control using Traditional Compensators . . . 24

3.2.2 Flow Control using Flow Sharing Compensators . 26 
5 Dynamic Analysis 33

5.1 Mathematical Model . . . . . . . . . . . . . . . . 34

5.2 Pump Stability . . . . . . . . . . . . . . . . 36

5.2 .1 Load Sensing Systems . . . . . . . . . . . . 36

5.2 .2 Flow Control Systems . . . . . . . . . . . . 37

5.3 Damping . . . . . . . . . . . . . . . . . 39

5.3.1 Active Control of the Inlet Orifice . . . . . . . . . 39

5.3.2 Design and Control of the Outlet Orifice . . . . . . 42

6 A Flexible Working Hydraulic System 45

6.1 Pump Controller . . . . . . . . . . . . . . . . 45

6.2 Combining Flow Control and Load Sensing . . . . . . . 46

6.3 Combining Open-centre and Flow Control . . . . . . . . 48

6.4 Combining Load Sensing and Open-centre . . . . . . . . . 51

6.5 Complete System Solution . . . . . . . . . . . . . . 53

7 Experimental Results $\quad \mathbf{5 5}$

7.1 Energy Efficiency Improvements _. . . . . . . . . . 55

7.2 Outlet Orifice Damping Contribution . . . . . . . . . . 59

7.3 Flexible System Characteristics . . . . . . . . . . . . 61

7.3.1 Flow Matching Problem . . . . . . . . . . . . 61

7.3.2 Dynamic Characteristics . . . . . . . . . . . . . 62

7.3.3 Load Dependency . . . . . . . . . . . . . . . 64

$\begin{array}{lll}8 & \text { Discussion } & 67\end{array}$

9 Conclusions $\quad 71$

$\begin{array}{ll}10 \text { Outlook } & 73\end{array}$

11 Review of Papers $\quad 75$

\section{Appended papers}

$\begin{array}{lll}\text { I } & \text { Flow versus Pressure Control of Pumps } & 87\end{array}$

II Dynamic Analysis of Flow Controlled Systems 115 
III Optimized Damping Using the Meter-out Orifice 141

IV A Hybrid of Pressure and Flow Control 161

V Efficient System with Open-centre Characteristics 181

VI A Flexible Working Hydraulic System 201 


\section{Nomenclature}

The quantities used in this thesis are listed in the table. Capital letters are used for linearized and Laplace transformed variables.

\begin{tabular}{lll}
\hline Quantity & Description & Unity \\
\hline$A_{c}$ & Cylinder area & $\mathrm{m}^{2}$ \\
$A_{c_{1}}$ & Compensator area exposed to control pressure & $\mathrm{m}^{2}$ \\
$A_{c_{2}}$ & Compensator area exposed to control pressure & $\mathrm{m}^{2}$ \\
$A_{o c}$ & Opening area in the open-centre path & $\mathrm{m}^{2}$ \\
$A_{s}$ & Directional valve opening area & $\mathrm{m}^{2}$ \\
$B_{p}$ & Viscous friction coefficient & $\mathrm{Ns} / \mathrm{m}$ \\
$C_{q}$ & Flow coefficient & - \\
$D_{p}$ & Pump displacement & $\mathrm{m}^{3} / \mathrm{rev}$ \\
$F_{s}$ & Compensator spring stiffness & $\mathrm{N}$ \\
$K_{c_{a}}$ & Flow-pressure coefficient for the inlet orifice & $\mathrm{m}^{3} / \mathrm{Pa} \mathrm{s}$ \\
$K_{c_{a p t}}$ & $K_{c_{a}}$ which gives the highest damping & $\mathrm{m}^{3} / \mathrm{Pa} \mathrm{s}$ \\
$K_{c_{b}}$ & Flow-pressure coefficient for the outlet orifice & $\mathrm{m}^{3} / \mathrm{Pa} \mathrm{s}$ \\
$K_{c_{b} \text { opt }}$ & $K_{c_{b}}$ which gives the highest damping & $\mathrm{m}^{3} / \mathrm{Pa} \mathrm{s}$ \\
$L_{p}$ & Pump inductance & $\mathrm{Pa} \mathrm{s} / \mathrm{m}^{3}$ \\
$m_{L}$ & Load mass & $\mathrm{kg}$ \\
$n_{p}$ & Pump shaft speed & $\mathrm{rev} / \mathrm{s}$ \\
$P_{a}$ & Pressure on the piston side of the cylinder & $\mathrm{Pa}$ \\
$P_{a_{\text {max }}}$ & Maximum pressure on the piston side & $\mathrm{Pa}$ \\
$P_{b}$ & Pressure on the piston rod side of the cylinder & $\mathrm{Pa}$ \\
$p_{L}$ & Load pressure & $\mathrm{Pa}$ \\
$p_{L_{\text {max }}}$ & Maximum load pressure & $\mathrm{Pa}$ \\
$p_{o c}$ & Pressure in the open-centre path & $\mathrm{Pa}$ \\
$P_{p}$ & Pump pressure & $\mathrm{Pa}$ \\
$p_{r}$ & Reduced pressure & $\mathrm{Pa}$ \\
& &
\end{tabular}


$p_{s} \quad$ Supply pressure

$\mathrm{Pa}$

$Q_{a} \quad$ Flow into the cylinder

$\mathrm{m}^{3} / \mathrm{s}$

$Q_{b} \quad$ Flow out of the cylinder

$\mathrm{m}^{3} / \mathrm{s}$

$q_{L} \quad$ Load flow

$\mathrm{m}^{3} / \mathrm{s}$

$Q_{p} \quad$ Pump flow

$q_{p_{\max }} \quad$ Maximum pump flow

$\mathrm{m}^{3} / \mathrm{s}$

$Q_{p_{\text {ref }}} \quad$ Pump flow demand

$\mathrm{m}^{3} / \mathrm{s}$

$q_{\text {virtual }}$ Virtual open-centre flow

$\mathrm{m}^{3} / \mathrm{s}$

$\mathrm{m}^{3} / \mathrm{s}$

$s \quad$ Laplace variable

$U \quad$ Mechanical gear ratio

$V_{a} \quad$ Volume at the piston side of the cylinder

$1 / \mathrm{s}$

$V_{b} \quad$ Volume at the piston rod side of the cylinder

$V_{p} \quad$ Pump hose volume

$\mathrm{m}^{3}$

$X_{p}$

Piston position

$\mathrm{m}^{3}$

$x_{v}$

Valve position

$\mathrm{m}$

$x_{v}$

Bulk modulus

$\mathrm{m}$

$\varepsilon_{p}$

Pump displacement setting

$\gamma_{i} \quad$ Parameter for the inlet orifice

$\gamma_{o} \quad$ Parameter for the outlet orifice

$\delta_{h_{\max }} \quad$ Maximum damping

$\Delta P_{p} \quad$ Pump pressure margin

$\mathrm{Pa}$

$\Delta P_{p_{r e f}}$

Pump pressure margin demand

$\mathrm{Pa}$

$\kappa \quad$ Cylinder area ratio

$\xi \quad$ Parameter

$\rho \quad$ Density

$\sigma \quad$ Parameter

$G_{o} \quad$ Open-loop transfer function

$G_{p_{F C}} \quad$ Pump transfer function

$G_{p_{L S}} \quad$ Pump transfer function

$G_{v_{a}} \quad$ Inlet valve transfer function

$G_{v e_{a}} \quad$ Inlet valve transfer function

$G_{v_{b}} \quad$ Outlet valve transfer function

$H_{s} \quad$ Pump hose transfer function

$Z_{L} \quad$ Load transfer function 


\section{1 \\ Introduction}

Fluid power systems are used in a wide range of applications, mobile as well as industrial. In mobile machinery, such as construction, forestry and agricultural machines, fluid power is used for both propulsion systems and working hydraulics. An example of working hydraulics is the system controlling the boom and bucket motion of an excavator. This thesis covers the area of working hydraulic systems for mobile machines. Innovative system designs are proposed and discussed in relation to both existing and not yet commercially available working hydraulic systems for mobile machinery.

\section{$1.1 \quad$ Background}

There are several reasons for preferring hydraulic systems to other technologies. Hydraulic components have a superior power density compared to, for example, electrical components [Rydberg, 2009] [Thiebes, 2011]. It is simple and efficient to realize linear movements of large forces by using differential cylinders [Murrenhoff et al., 2014]. Furthermore, hydraulic systems have the ability to handle force impacts, which makes them more robust than, for example, mechanical transmissions [Eriksson, 2010]. Hydraulic components are generally available at lower cost compared to other technologies, especially for high power applications [Rydberg, 2009]. Other properties of hydraulic systems are their good heat transfer capability and the simple overload protection [Yuan et al., 2014].

Hydraulic systems also present some challenges. The most important one concerns their energy efficiency [Weber and Burget, 2012] 
[Grey, 2011]. Much progress has been made in making the individual components more efficient [Vael et al., 2009] [Achten, Vael, et al., 2011]. However, each component has its optimum working condition, which often leads to poor overall system efficiency [Achten, Vael, et al., 2011] [Inderelst, 2013].

When improving energy efficiency in hydraulic systems, the trend is to use additional components and sensor-dependent functionality [Weber and Burget, 2012] [Eriksson, 2007]. Meanwhile, less attention has been paid to the dynamic properties. A hydraulic system with poor dynamic properties has a tendency to oscillate, which has a negative impact on both the productivity of the application and the comfort of the operator.

\subsection{Aims}

The introduction of electrically controlled components in the field of hydraulic systems has opened up new possibilities [Brand, 2012]. One aim of this thesis is to improve the energy efficiency and the dynamic performance of working hydraulic systems for mobile machines without adding additional components or increasing complexity. The only difference between the systems proposed in this thesis and commercially available systems is that the traditional hydro-mechanical pump controller is replaced by an electrical controller. This makes the pump controller more flexible with the possibility to control both flow and pressure.

Historically, different hydraulic systems have been developed for different types of machines. A further aim of this thesis is therefore to propose a more flexible hydraulic system layout which has the possibility to change static and dynamic characteristics online to fit a specific machine, working cycle or operator.

Finally, the solutions proposed in this thesis should also be validated experimentally to verify the expected performance.

\subsection{Delimitations}

This thesis concerns the energy efficiency and dynamic characteristics of working hydraulic systems in mobile machines. Other aspects, such as manufacturing and marketing, are not taken up. Industrial hydraulics and propulsion systems are not included in this work. This thesis is also 
limited to the hydraulic system; the combustion engine or the electrical motor powering the hydraulic pump is therefore not included. The field of digital hydraulics is also not included in this thesis.

\subsection{Contribution}

The most important contribution of this thesis is a deeper understanding of how energy efficiency and dynamic characteristics can be improved in working hydraulic systems in general and flow control systems in particular. Novel ways of designing and controlling the directional valves in order to optimize damping are proposed and demonstrated. A new solution to the flow matching problem is proposed and its functionality is verified by experiments. A flexible hydraulic system design where the operator can change system characteristics online is also proposed and demonstrated.

\subsection{Research Method}

This thesis has been influenced by the hypothetico-deductive method of research [Johansson, 2003]. Typically, a hypothesis is formed and then tested using mathematical analysis, modelling and simulation, and experimental verification. An example from this thesis is the energy efficiency improvements of flow control systems compared to load sensing systems. The hypothesis is that changing from pressure control of the pump to flow control would increase energy efficiency. A simulation model is built of the existing load sensing system. Experimental data is collected from the existing system and uncertain parameters in the simulation environment are tweaked in order for the model to agree with reality to an acceptable degree. Parts of the model can now be changed to accurately represent the new system. In this case, it means that the pump controller is changed. The hypothesis can now be tested and confirmed in the simulation environment. However, some important physical phenomena might have been overlooked in the simulation models and the new system needs to be validated in a test rig. The test rig is then rebuilt and a final validation can be performed. 


\subsection{Thesis Outline}

A review of working hydraulic systems in mobile machines is made in chapter 2 . Both existing and not yet commercially available systems are discussed. Flow control systems are studied in detail in chapter 3. An energy efficiency analysis comparing flow control and load sensing is performed in chapter 4 and a dynamic analysis comparing the two systems is made in chapter 5 . In chapter 6 , a flexible working hydraulic system with changeable characteristics is proposed. It is possible to realize load sensing, flow control, open-centre or a mix of the three systems. Experimental results are shown in chapter 7. Energy efficiency improvements for flow control compared to load sensing are shown and the damping contribution of the outlet orifice in the directional valve are exemplified. A solution to the flow matching problem is also demonstrated and the static and dynamic differences between different control modes of the flexible hydraulic system are presented. A discussion is given in chapter 8, conclusions in chapter 9 and an outlook in chapter 10. Finally, all appended papers are briefly summarized in chapter 11 . 


\section{2 \\ Mobile Working Hydraulic Systems}

Mobile hydraulic applications distinguish themselves from other hydraulic applications, such as industrial hydraulics, because the pressure and flow demand varies greatly over time and between different functions. Unlike other hydraulic applications, several functions are often supplied by one single pump. This means that the total installed power on the actuator side is generally considerably higher than the installed pump power. This is possible because the actuators almost never require their maximum power at the same time. The need for only one system pump makes the hydraulic system compact and cost-effective.

Fluid power systems have been used successfully in mobile machines for several decades. Because of the machines' versatility, different hydraulic systems have been developed for different applications. Important properties of hydraulic systems are, among others, energy efficiency, controllability, damping and system complexity. However, the order of importance of these properties varies for different applications. This chapter gives an overview of the most commonly used working hydraulic systems of today. It also presents some innovative system designs that have not yet been commercialized but are attracting considerable attention both in industry as well as academia. Energy efficiency, controllability, damping and system complexity are discussed and compared. 


\subsection{Valve Controlled Systems}

Today, most hydraulic systems in mobile machines are operated with open-centre valves and fixed displacement pumps, see figure 2.1a. Such systems can be considered to be relatively simple, robust and costeffective, but also often energy-inefficient. These systems suffer from load interference, which means that the pressure level at one load can significantly influence the velocity of other actuators. Furthermore, the flow rate is not only dependent on spool position, but also on load pressure, often referred to as load dependency. From a controllability point of view, this is often considered a drawback. From a dynamics point of view load dependency is a desired property. It gives the system a naturally high damping, which means that the system is less prone to oscillations. To obtain damping from a valve, the flow has to increase when the pressure drop across the valve increases and vice versa. Damping is a preferred property when handling large inertia loads, for example the swing function of a mobile crane.

Constant pressure systems improve controllability compared to opencentre systems since they have no load interference issues. Other characteristics, such as efficiency and dynamics, are similar to open-centre systems and complexity is slightly higher, mainly because constant pressure systems often use a pressure controlled variable displacement pump. It is, however, possible to increase energy efficiency of constant pressure systems by, for example, using secondary control [Palmgren, 1988] or introducing an intermediate pressure line [Dengler et al., 2012].

Load sensing systems improve energy efficiency compared to opencentre and constant pressure systems by continuously adapting their pressure just above the highest load. A pressure difference, usually around 20-30 bar, between pump and load is necessary to overcome losses in hoses and valves. This pressure margin is often set substantially higher than necessary to ensure it is high enough at all operational points. A load sensing valve is often equipped with a pressure compensator which controls the pressure drop across the directional valve, see figure 2.1b. Different loads can thereby be operated almost without load interference and load dependency, giving excellent controllability properties. An early review of load sensing systems was made by [Andersson, 1980].

One weakness of load sensing systems using pressure compensated 


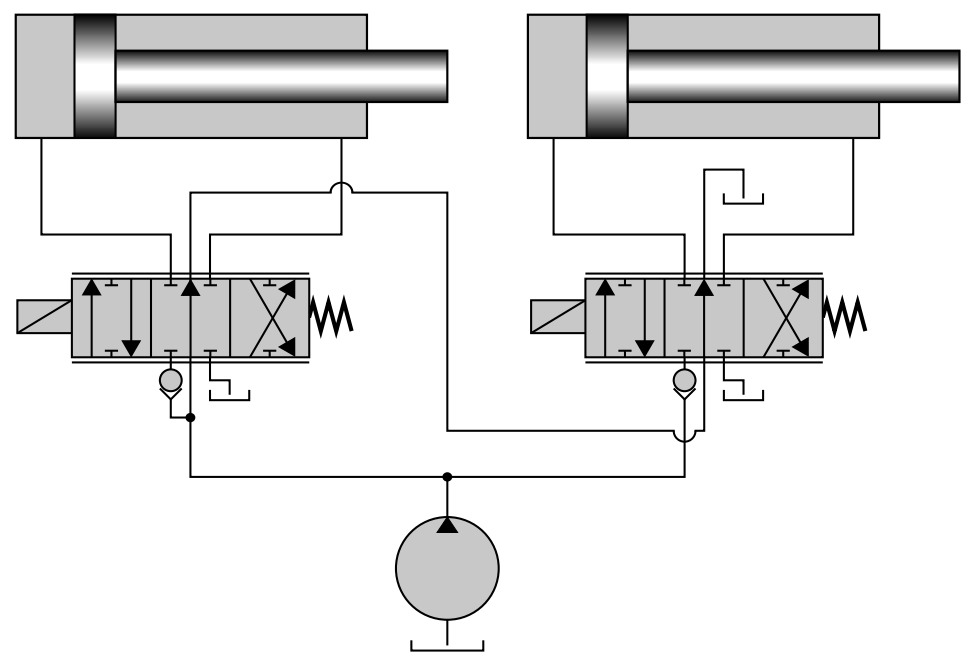

(a) System with open-centre valves and a fixed displacement pump.

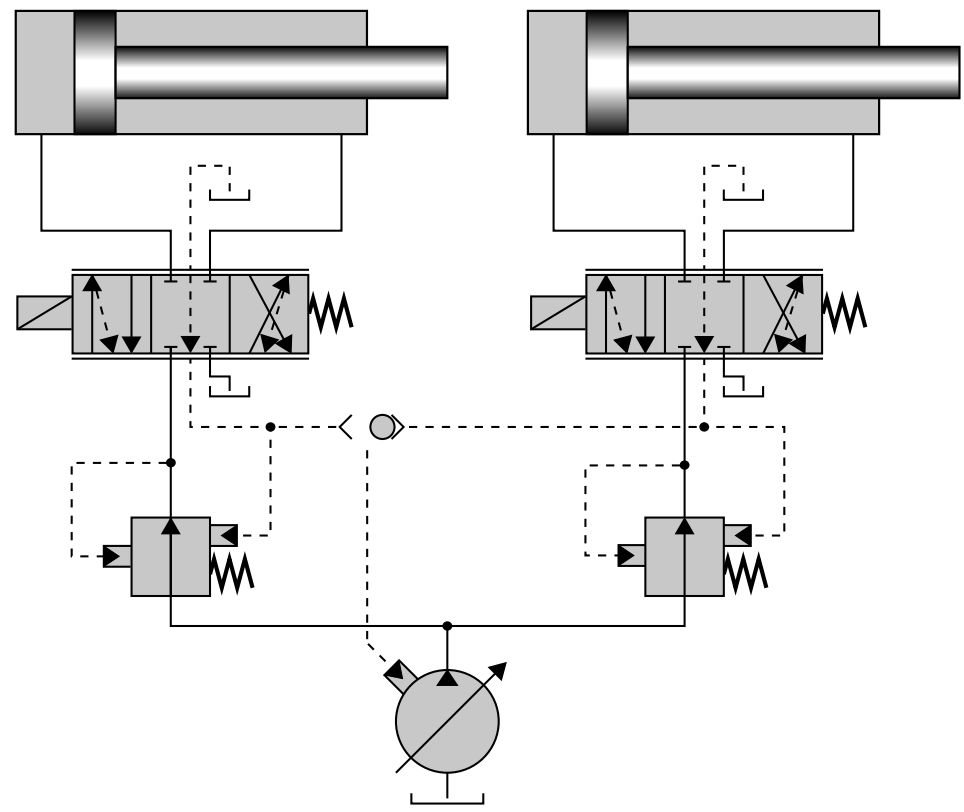

(b) System with pressure compensated load sensing valves and a pressure controlled variable displacement pump.

Figure 2.1 Different system designs commonly used for the working hydraulics in mobile applications. 
valves is the hydraulic damping. The primary design endeavours to achieve low influence on the flow from the load pressure. This decreases the damping capability of the valve. When using pressure compensators, only the outlet orifice in the directional valve will provide damping to the system, see papers [III] and [XI]. Furthermore, the pump in load sensing systems is controlled in a closed-loop control mode, where the highest load is the feedback signal. At certain points of operation, this might result in an oscillatory behaviour. A complete investigation of load sensing systems and their dynamic properties, including pump controllers, can be found in [Krus, 1988]. The dynamics of pressure compensated valves have been studied in, for example, [Pettersson et al., 1996] and [Wu et al., 2007].

To improve energy efficiency but still maintain load dependency and high damping, systems based on variable displacement pumps and opencentre valves have been developed. One type of solution is to control the pump in order to keep the flow through the open-centre path constant. The controllability is similar to open-centre systems, which means a smooth control with high damping. Power losses are generally higher than in closed-centre load sensing systems but not as high as in opencentre systems because of the variable pump. However, open-centre variable pump systems have power losses in neutral while closed-centre load sensing systems do not. Another type of solution is to use a flow controlled pump and open-centre valves. The pump displacement setting can be controlled either by the joystick pilot pressure or by the flow rate in the open-centre path. These systems are studied in detail in section 2.4.

A step forward from systems using conventional spool valves is to decouple the inlet and the outlet orifices in the directional valve. Numerous configurations for individual metering systems have been developed, both in academia as well as in industry [Eriksson and Palmberg, 2011]. These concepts provide a higher degree of freedom as all four orifices are separated and can be controlled individually. The main benefit of this increased freedom is that the flow paths can be changed during operation. Four different operational cases can be identified; normal, regenerative, energy-neutral and recuperative [Eriksson, 2010]. 


\subsection{Valveless Systems}

One hot research topic in the area of mobile hydraulics is systems in which the control valves are eliminated along with the metering losses. Multiple concepts have been developed, including pump controlled actuators, hydraulic transformers and electro-hydrostatic actuators [Williamson and Ivantysynova, 2007]. Such systems are not yet common commercially in mobile applications but can be found in, for example, the aerospace industry [Raymond and Chenoweth, 1993].

Instead of using one pump to supply all actuators, every actuator has a dedicated pump in pump controlled actuator systems. To control the speed, the pump displacement setting is used as the final control element. All losses are thereby ideally eliminated. In reality, the losses are heavily dependent on the efficiency of the system pumps [Williamson and Ivantysynova, 2007]. These systems can principally be differentiated in two different circuit layouts, either with the pump arranged in a closed circuit [Rahmfeld and Ivantysynova, 2001] [Rahmfeld, Ivantysynova, and Weber, 2004] or in an open circuit [Heybroek, 2008].

A hydraulic transformer converts an input flow at a certain pressure level to a different output flow at the expense of a change in pressure level, ideally maintaining the hydraulic power. One way of realizing a transformer is to combine two hydraulic machines, where at least one has a variable displacement. Efficiency is limited, however, mainly because at least one of the machines will operate under partial loading conditions [Werndin and Palmberg, 2003]. In recent years, an innovative transformer concept has been developed by the Dutch company Innas BV [Achten, Fu, et al., 1997]. The conventional transformer with two hydraulic machines has been replaced by one axial piston unit, thereby avoiding partial loading conditions. A mean efficiency of $93 \%$ in a broad region of operation has been reported [Achten, Vael, et al., 2011].

The main component in electro-hydrostatic actuator systems, often referred to as EHA, is a fixed displacement bidirectional hydraulic pump. An electric motor is usually used to power the pump, enabling active control of the rotational speed and thereby the flow to the actuator. A conventional EHA requires a symmetrical actuator in order to ensure flow balance, but solutions for handling asymmetrical cylinders have been proposed [Gomm and Vanderlaan, 2009]. In EHA systems, the pump only operates when control action is needed. 


\subsection{System Summary}

When more than one load is actuated, often only the heaviest load can be operated efficiently in single pump systems. This issue is resolved in valveless systems. When all loads have their own dedicated pump, the pressure can always be matched against the present load. One has to bear in mind, however, that valveless systems may require several valves to handle, for example, asymmetric cylinder actuation and meet safety requirements [Williamson and Ivantysynova, 2007] [Heybroek, 2008].

Furthermore, since all actuators have their own dedicated pump in the valveless concepts, each one has to be sized to handle maximum speed. A typical example of a dimensioning motion is the lowering boom motion in a wheel loader. The lowering flow can be several times higher than the maximum pump flow in a similar valve controlled system. The difference is that all flow has to be handled by the pump in valveless system layouts. In single pump systems, the pump can be downsized since not every load is actuated at full speed simultaneously very often. For these reasons, the total installed displacement tends to be high in valveless systems compared to single pump systems.

\subsection{Single Pump Systems using Conventional Spool Valves}

When improving energy efficiency in fluid power systems, the trend is to use additional components and more sophisticated control algorithms [Weber and Burget, 2012] [Eriksson, 2007]. Meanwhile, basic constraints such as space requirements, initial cost and control complexity are often overlooked. This thesis therefore focuses on single pump systems using conventional spool valves. Both pressure and flow controlled pumps are discussed.

\subsubsection{Open-centre}

Open-centre systems are used together with fixed displacement pumps and have a valve design with a channel in the centre position, directing all flow to tank when no valve is activated. When a valve is shifted from its neutral position, the open-centre channel begins to close and the pump pressure increases. Figure 2.2a shows an example of the opening areas as 


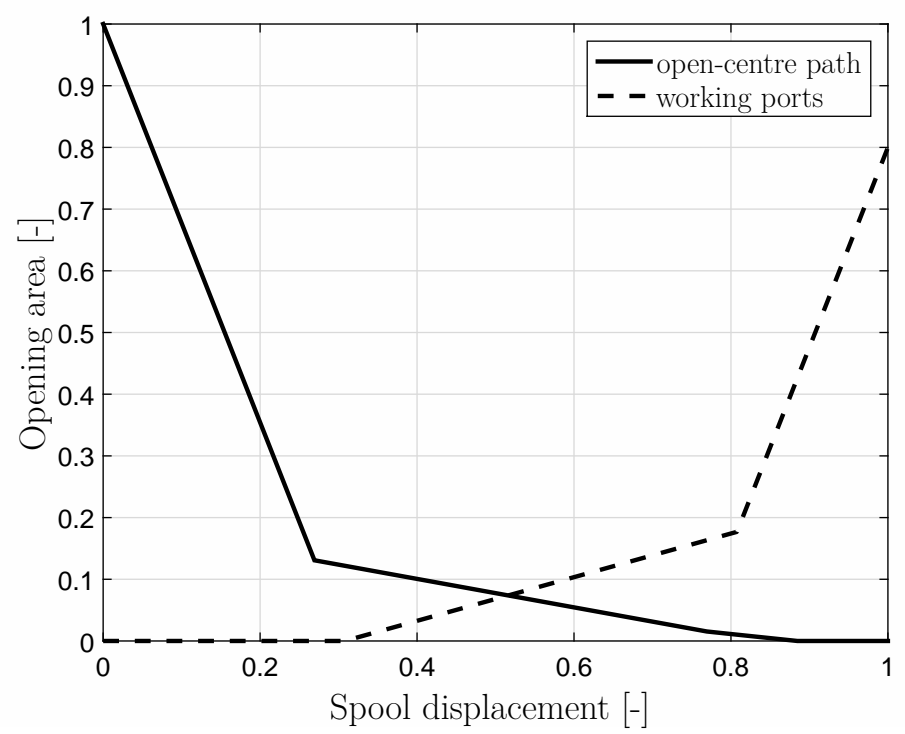

(a) An example of opening areas as a function of spool displacement for an open-centre valve.

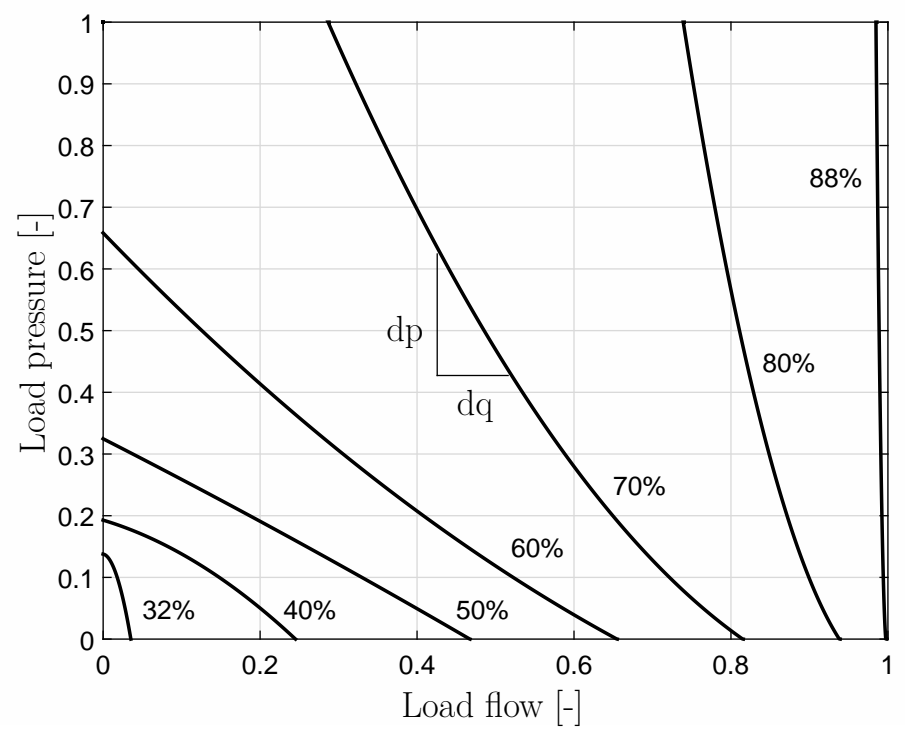

(b) Load pressure as a function of load flow for different spool positions. The opening areas from figure $2.2 \mathrm{a}$ have been used. The damping contribution from the opencentre path is directly proportional to the slope of the curve, $-d q / d p$.

Figure 2.2 Open-centre system characteristics. 
a function of spool displacement. There will be a flow to the load when the pump pressure is higher than the load pressure. The rate of this flow is thus not only dependent on spool displacement, but also on load pressure, see figure $2.2 \mathrm{~b}$. This load pressure sensitivity gives the operator a pressure control, which means that he or she can control the acceleration of the load, giving the system a smooth control with high damping. A non-skilled operator might experience this pressure sensitivity as an inconsistency and it can then be regarded as a disturbance. However, a skilled operator can use this information feedback from the system to advantage and increase the machine's controllability. A major drawback with open-centre systems is, however, poor energy efficiency in most points of operation due to the fixed displacement pump.

\subsubsection{Load Sensing}

Load sensing systems improve the energy efficiency compared to opencentre systems by continuously adapting their pressure just above the highest load, see figure 2.3. This means that a specific spool displacement results in a certain flow, regardless of the load pressure. This is also true for simultaneous movements of loads if pressure compensators are used. The pressure insensitivity makes load sensing systems easy to

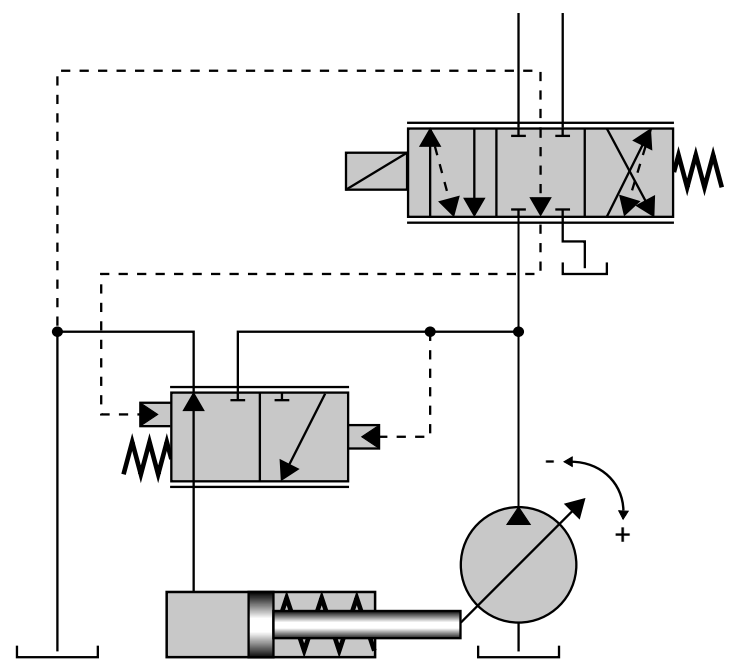

Figure 2.3 The pump in load sensing systems is controlled in order to maintain the pump pressure at a certain level above the highest load pressure. 
operate for velocity or position control of low inertia loads. With high inertia loads, however, the operation becomes jerky because of the low damping.

\subsubsection{Open-centre Load Sensing}

To overcome the shortcomings in load sensing systems, characterized by low damping and lack of pressure control, open-centre load sensing valves have been developed. They are a modification of the conventional and well accepted open-centre valve to work more efficiently with variable displacement pumps. One solution is to add a metering orifice upstream of the open-centre path in the directional valve. The pump is controlled in order to maintain a constant pressure drop across the metering orifice, see figure 2.4. This will in turn keep the by-pass flow through the open-centre channel constant. Activating a valve will gradually close the by-pass orifice, creating a pressure drop in the by-pass flow and increase the pump pressure. The spool displacement will thus determine the pump outlet pressure, similar to a conventional open-centre system, which gives the system a smooth control with high damping. However, the efficiency is lower than in closed-centre load sensing systems because

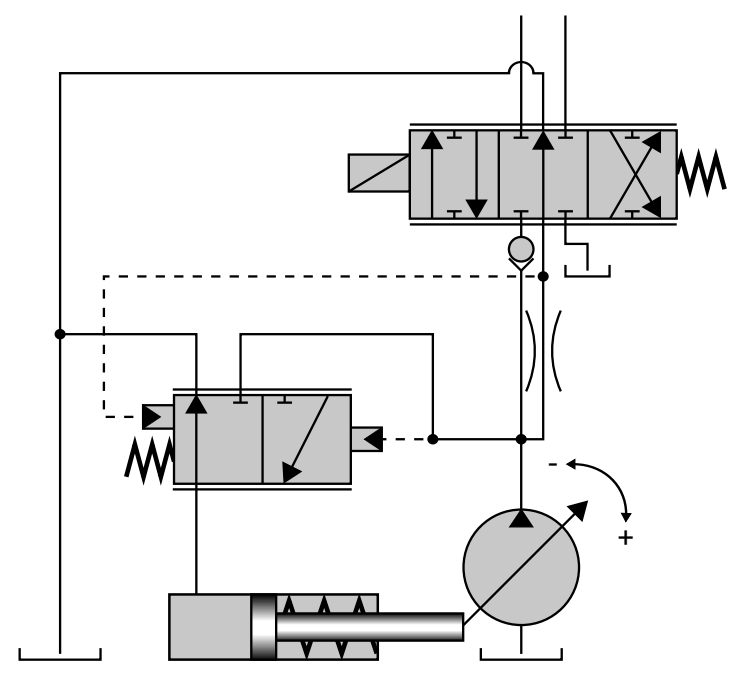

Figure 2.4 The pump in open-centre load sensing systems is controlled in order to maintain a constant pressure drop across the metering orifice, thereby keeping the flow through the open-centre path constant. A standard load sensing pump is used. 
of the power losses in the open-centre gallery. An advantage is that the same pump controller as in conventional load sensing systems can be used. The system is called open-centre load sensing because of the combination of a standard load sensing pump and open-centre valves.

\subsubsection{Negative Load Sensing}

Another way to combine a pressure controlled pump and open-centre valves is to add a metering orifice downstream of the open-centre channel in the directional valve. The pump is then controlled in order to maintain a constant pressure upstream of the metering orifice, see figure 2.5. This will keep the by-pass flow in the open-centre channel constant, similar to open-centre load sensing. The difference between the two system layouts is that the pump controller works the other way around. When sensing a pressure increase, the pump displacement is decreased. This system is therefore called negative load sensing.

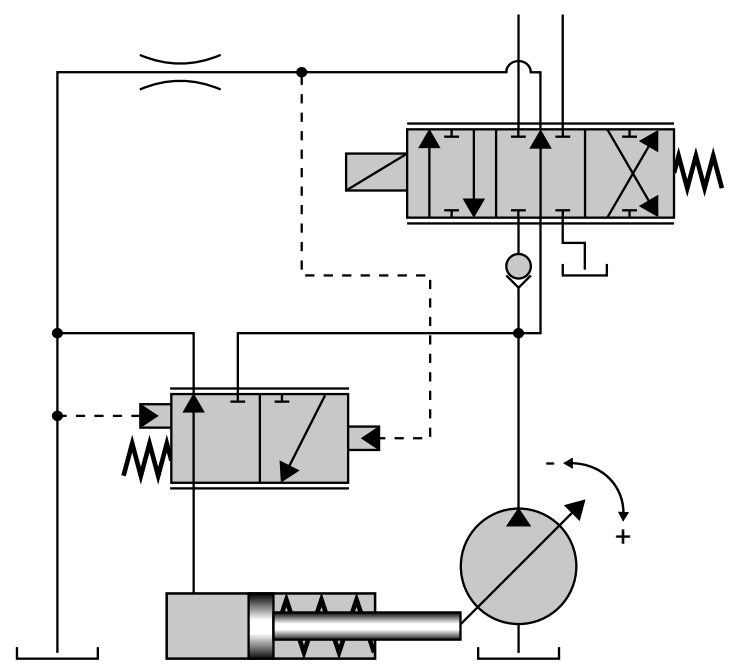

Figure 2.5 The pump in negative load sensing systems is controlled in order to maintain a constant pressure upstream of the metering orifice, thereby keeping the flow through the open-centre path constant. A load sensing pump with an inverted controller is used. 


\subsubsection{Negative Flow Control}

An alternative to a pressure controlled pump is to control the pump displacement setting. This could be done by, for example, an internal hydro-mechanical feedback of the pump displacement setting [Swash-plate pump K3VL]. The pressure upstream of a metering orifice, located in the open-centre channel downstream of the directional valve, is used to control the pump displacement setting, see figure 2.6. When the valve is in neutral position, the pump is de-stroked to a low displacement, directing all flow through the open-centre path. As a directional valve is opened, the open-centre path is gradually closed, increasing the pump pressure. When the load pressure is overcome, part of the flow is directed to the load. This decreases the pressure upstream of the metering orifice, making the pump increase its displacement. When the open-centre path is completely closed, the pressure upstream of the metering orifice is at a minimum level and the pump is thus at maximum displacement. This system is called negative flow control since a decreased control pressure gives an increased pump displacement setting, see for example [Choeng, 2011] and [Liao et al., 2012]. An advantage with this system is that the flow through the open-centre path decreases with increased pump flow. This is different compared to open-centre

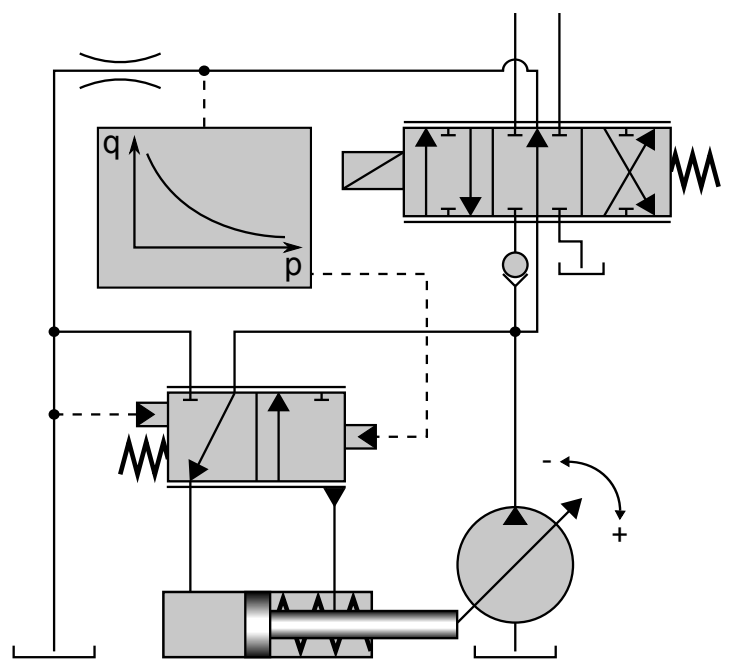

Figure 2.6 The pump in negative flow control systems is controlled by the pressure upstream of the metering orifice. The pump displacement setting is increases with a decreased control pressure. 
load sensing and negative load sensing, where the pump is controlled in order to maintain a constant open-centre flow.

\subsubsection{Positive Flow Control}

An alternative to negative flow control is to control the pump displacement setting using the highest joystick pilot pressure, see figure 2.7. When no joystick is activated, the pump displacement setting is low and all flow is directed to tank. Activating a joystick will increase the pump flow and gradually close the open-centre path, which increases the pump pressure. There will be a flow to the load when the pump pressure is higher than the load pressure. This system is called positive flow control since the flow increases with increased joystick signal [Cobo et al., 1999]. One drawback with this system layout is simultaneous operation of several functions. Since the pump displacement setting is determined by the highest joystick pilot pressure, flow demands from different loads are not added. Furthermore, it is essential to have knowledge about every flow consumer in the system since there is no feedback signal to the pump controller. Therefore, it might be problematic to connect auxiliary functions, for example support legs, to the existing hydraulic system. An advantage with positive flow control is the possibility to use a valve in

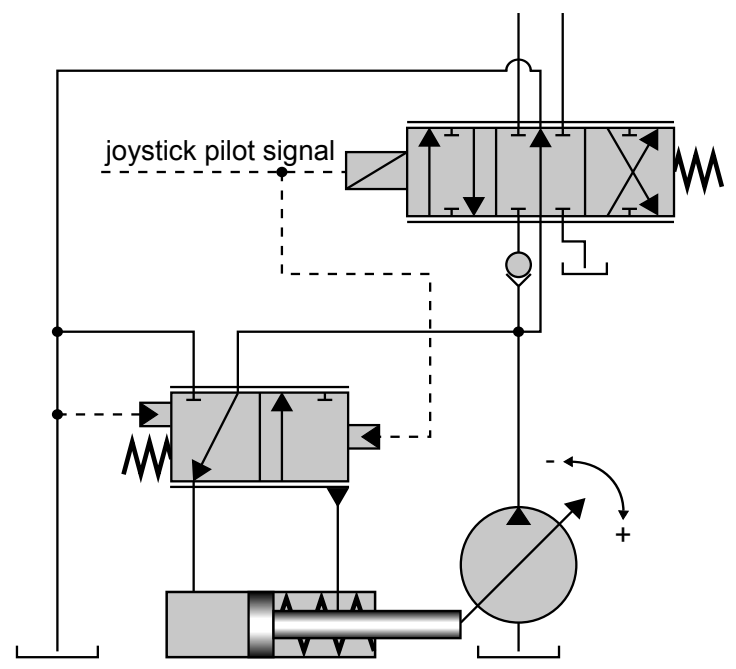

Figure 2.7 The pump and the valves are controlled by the operator's joystick signals in positive flow control systems. The highest joystick pilot pressure gives a reference displacement signal to the pump controller. 
which the open-centre path is closed at a relatively small spool position. This gives a pressure control with smooth control and high damping for low velocities and velocity control with no pressure sensitivity for high velocities.

\subsubsection{Flow Control}

A step forward from positive flow control is to replace the hydromechanical pump controller with an electrical controller. It would then be possible to add flow demands from different loads. Furthermore, it would be possible to use closed-centre spool valves equipped with pressure compensators, thus eliminating load interaction issues. This results in a system layout similar to load sensing, but with one principal difference: instead of controlling the pump in a closed-loop pressure control mode, an open-loop control is used where the pump displacement setting is based on the sum of all requested load flows. Sensors are not required to achieve the desired functionality and all components needed are available on the market [Latour, 2006]. In this work, the system will be referred to as flow control. Such concepts are studied in detail in chapter 3. An energy efficiency comparison between load sensing and flow control is made in chapter 4 and a dynamic comparison between the two systems is performed in chapter 5 . In chapter 6 , the concept is extended to allow changeable system characteristics. Experimental results demonstrating some of the findings in this thesis are shown in chapter 7 . 


\section{3 \\ Flow Control Concepts}

In mobile hydraulic systems, the actuation of different loads is controlled by joystick signals. These signals pose either a flow or pressure demand from the operator. In applications with high demands as regards controllability, the signals from the operator often correspond to flow demands. One example is load sensing systems equipped with pressure compensators. Nevertheless, the pump in these kinds of systems is still often pressure controlled.

In systems where the operator's signals correspond to flow demands, it seems more natural to also control the pump by flow. This approach has some benefits regarding energy efficiency, dynamic characteristics and increased flexibility compared to load sensing systems. It also presents some challenges, for example the design of the compensator.

The idea of flow control is to use the joystick signals to control the pump flow and the valve openings simultaneously, see figure 3.1. The pump displacement setting is controlled according to the sum of all requested load flows.

In the literature, different researchers have used different names for systems where the pump displacement setting is controlled according to the sum of all requested load flows. Initial considerations regarding this pump control strategy were patented by [Stenlund, 1988] under the name "Electrohydraulic guide system". Similar ideas were published by [Zähe, 1993] under the name "Summenstromreglerung", which roughly means "Aggregate flow control". However, suitable electro-hydraulic components were not available until sev- 


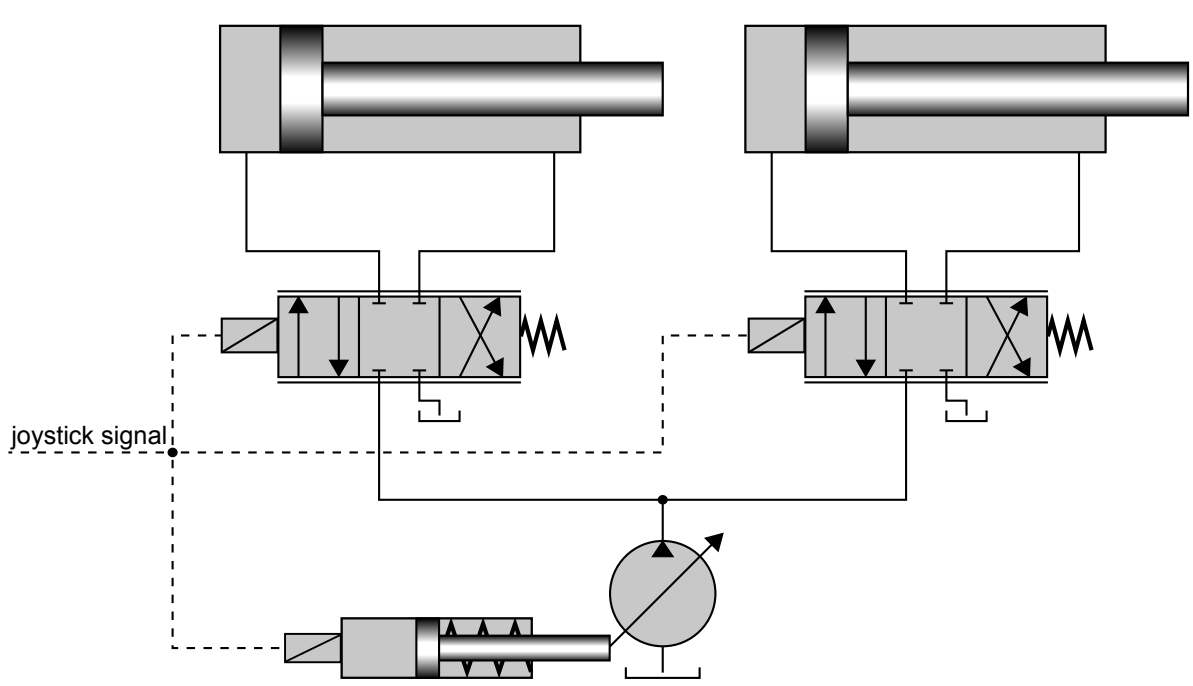

Figure 3.1 Simplified schematic of a flow control system. The pump displacement setting and the valve openings are controlled simultaneously by the operator's joystick signals.

eral years later. In 2004, research intensified [Jongebloed et al., 2004] [Djurovic and Helduser, 2004] [Djurovic, Helduser, and Keuper, 2004]. [Jongebloed et al., 2004] used pressure sensors at all load ports for the valve control, calling the system "LCS - Load-Control-System". [Djurovic, 2007] studied a system design with traditional pressure compensators, which requires the pump flow to be matched against the sum of all load flows, sometimes referred to as the "flow matching problem" [Eriksson and Palmberg, 2010]. Consequently, he used the notation "EFM - Electrohydraulic Flow Matching", which is a proprietary Bosch Rexroth brand name [Latour, 2006]. [Fedde and Harms, 2006] studied a similar system design and used the name "Flow Demand System". They used a bleed-off valve to deal with the flow matching and studied the pros and cons of overflow and underflow from the pump. [Finzel, 2010] continued Djurovic's work and introduced flow sharing compensators. These compensators distribute the entire pump flow relative to the individual valve openings, thus eliminating the flow matching problem. In later publications, [Scherer, 2015] proposed a solution to deal with a cylinder reaching its end stop and refer to the circuit as "Flow-OnDemand System".

When no function is activated, the pump is de-stroked, delivering no 
flow to the system, and all directional valves are closed. Activating a joystick will simultaneously open a valve and increase the displacement of the pump. Pressure is built up in the pump hose and when the pump pressure becomes higher than the load pressure there will be a flow to the actuator. When stationary, the flow delivered by the pump will go to the load. The pump pressure will therefore adapt itself to a level needed by the system, resulting in efficiency improvements compared to load sensing systems.

If more than one load is activated, all actuators will suffer from both load interference and load dependency. This can be resolved by introducing sensors to the system. [Stenlund, 1988] and [Zähe, 1993] used the velocities of the actuators as the main feedback signals for pump and valve control. [Jongebloed et al., 2004] used pressure sensors at all load ports for the valve control. To optimize energy efficiency, the valve at the highest load can be opened to its maximum while lighter loads are controlled by their valve openings.

These controllability issues can also be resolved by using pressure compensators. There will, however, be different demands on the compensator functionality compared to load sensing systems, but it also opens up new possibilities regarding valve control.

\subsection{Pressure Compensators}

In some mobile fluid power applications, load dependency and load interaction are undesired system characteristics. One example is forestry machines, where the operator wants to position the load accurately. Pressure compensators are commonly used in these kinds of applications to ensure good handling capabilities. Two different types of compensators can be realized: traditional and flow sharing. In applications with less demand for accuracy, it is also possible to take advantage of flow forces for the pressure compensation functionality.

\subsubsection{Traditional Compensators}

The most common design is to place the compensator upstream of the directional valve. The reduced pressure is then working against the load pressure and a preloaded spring, see figure 3.2a. The force equilibrium for the compensator, equation (3.1), together with the flow equation gives the flow across the directional valve. According to equation (3.2), 
the compensator spring force sets the pressure drop across the directional valve, making the flow load independent.

$$
\begin{gathered}
F_{s}+A_{c_{1}} p_{L}=A_{c_{1}} p_{r} \Leftrightarrow p_{r}-p_{L}=\frac{F_{s}}{A_{c_{1}}} \\
q_{L}=C_{q} A_{s} \sqrt{\frac{2}{\rho}\left(p_{r}-p_{L}\right)}=C_{q} A_{s} \sqrt{\frac{2}{\rho}\left(\frac{F_{s}}{A_{c_{1}}}\right)}
\end{gathered}
$$

It is also possible to achieve the same functionality by placing the compensator downstream of the directional valve. In that case, the supply pressure is working against the reduced pressure and a spring according to figure $3.2 \mathrm{~b}$. The force equilibrium, equation (3.3), together with the flow equation gives the same result, equation (3.2) compared with equation (3.4).

$$
\begin{gathered}
F_{s}+A_{c_{1}} p_{r}=A_{c_{1}} p_{s} \Leftrightarrow p_{s}-p_{r}=\frac{F_{s}}{A_{c_{1}}} \\
q_{L}=C_{q} A_{s} \sqrt{\frac{2}{\rho}\left(p_{s}-p_{r}\right)}=C_{q} A_{s} \sqrt{\frac{2}{\rho}\left(\frac{F_{s}}{A_{c_{1}}}\right)}
\end{gathered}
$$

These types of compensators are designed for use with a pressure controlled pump. In case of the pump being saturated, the supply pressure will drop, resulting in the compensator spool at the heaviest load opening completely. This function will lose speed and possibly even stop. Functions operated simultaneously at lower pressure levels will, however, move normally.

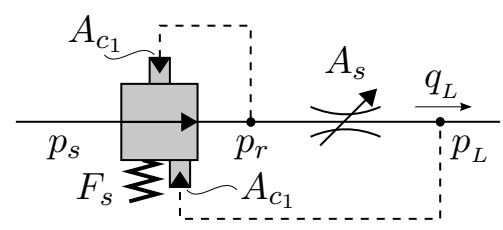

(a) The compensator is placed upstream of the directional valve.

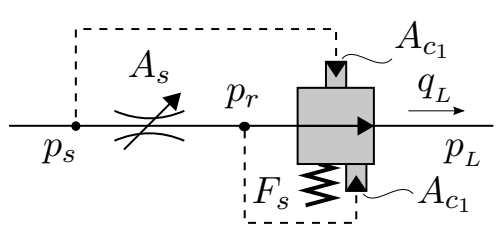

(b) The compensator is placed downstream of the directional valve.

Figure 3.2 Two different ways of realizing a traditional pressure compensator. The pressure drop across the directional valve is set by the compensator spring force. 


\subsubsection{Flow Sharing Compensators}

Another design is to implicate the highest load pressure into the compensator. When the pressure is actively controlled, this design is equivalent to the traditional compensator design. However, its characteristics are different when the pump is saturated. All functions will then be given the same priority, which means that all functions will decrease in speed. This flow sharing functionality can be achieved by placing the compensator either downstream or upstream of the directional valve.

If the compensator is located downstream of the directional valve, the reduced pressure is working against the highest load pressure and a spring, see equation (3.5) and figure 3.3a [Control block M6-15]. The pump pressure margin is defined according to equation (3.6) and the flow can be calculated according to equation (3.7).

$$
\begin{gathered}
A_{c_{1}} p_{r}=A_{c_{1}} p_{L_{\max }}+F_{s} \Leftrightarrow p_{r}=p_{L_{\max }}+\frac{F_{s}}{A_{c_{1}}} \\
\Delta p_{p}=p_{s}-p_{L_{\max }} \\
q_{L}=C_{q} A_{s} \sqrt{\frac{2}{\rho}\left(p_{s}-p_{r}\right)}=C_{q} A_{s} \sqrt{\frac{2}{\rho}\left(\Delta p_{p}-\frac{F_{s}}{A_{c_{1}}}\right)}
\end{gathered}
$$

The flow sharing pressure compensator placed upstream of the directional valve is similar to its traditional equivalent. Instead of a spring, two pressure signals that constitute the pump pressure margin are acting on the compensator, see figure 3.3b. Equation (3.6) together with

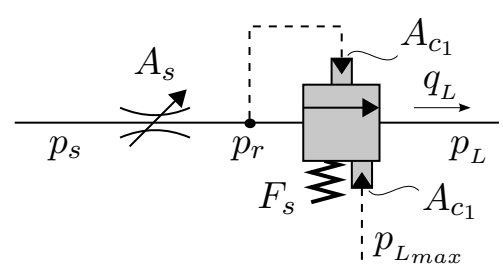

(a) The compensator is placed downstream of the directional valve.

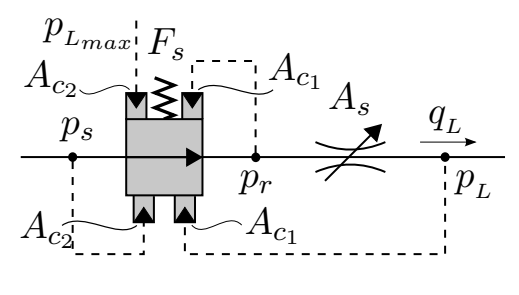

(b) The compensator is placed upstream of the directional valve.

Figure 3.3 Two different ways of realizing a flow sharing pressure compensator. The pressure drop across the directional valve is set by the pump pressure margin. 
the force equilibrium for the compensator, equation (3.8), gives the flow according to equation (3.9). The spring in this type of compensator is not required for the functionality. It can rather be used as a design parameter for, for example, prioritization [L90LS mobile control valve].

$$
\begin{array}{r}
A_{c_{2}} p_{s}+A_{c_{1}} p_{L}=A_{c_{2}} p_{L_{\max }}+A_{c_{1}} p_{r}+F_{s} \Leftrightarrow \\
\left(p_{r}-p_{L}\right)=\frac{A_{c_{2}}}{A_{c_{1}}}\left(p_{s}-p_{L_{\text {max }}}\right)-\frac{F_{s}}{A_{c_{1}}} \\
q_{L}=C_{q} A_{s} \sqrt{\frac{2}{\rho}\left(p_{r}-p_{L}\right)}=C_{q} A_{s} \sqrt{\frac{2}{\rho}\left(\frac{A_{c_{2}}}{A_{c_{1}}} \Delta p_{p}-\frac{F_{s}}{A_{c_{1}}}\right)}
\end{array}
$$

Flow sharing pressure compensators will distribute the entire pump flow relative to the individual valve openings also when the pump is saturated. A pressure controlled pump which has been saturated cannot control the pressure and can therefore be seen as a flow controlled pump. These compensators are therefore appropriate to use in flow control systems.

\subsection{Pump and Valve Control Approaches}

In flow control systems, the operator's joystick signals control the pump flow and the valve opening simultaneously. For this to work properly, the system software needs knowledge about every flow consumer. However, solutions for attaching auxiliary functions have been proposed [Mettälä et al., 2007] [Eriksson and Palmberg, 2010]. Different control approaches are possible depending on whether traditional or flow sharing compensators are used.

\subsubsection{Flow Control using Traditional Compensators}

When using traditional pressure compensators, see figure 3.4, the absolute flow through the valve is determined by the valve opening. This means that the pump flow has to be matched against the sum of all expected load flows. If this is not the case, two situations may occur.

The pump flow is too low This is the same case as when the pump is saturated in load sensing systems. The compensator spool at the highest load will open completely, resulting in a decrease in speed for that load. 


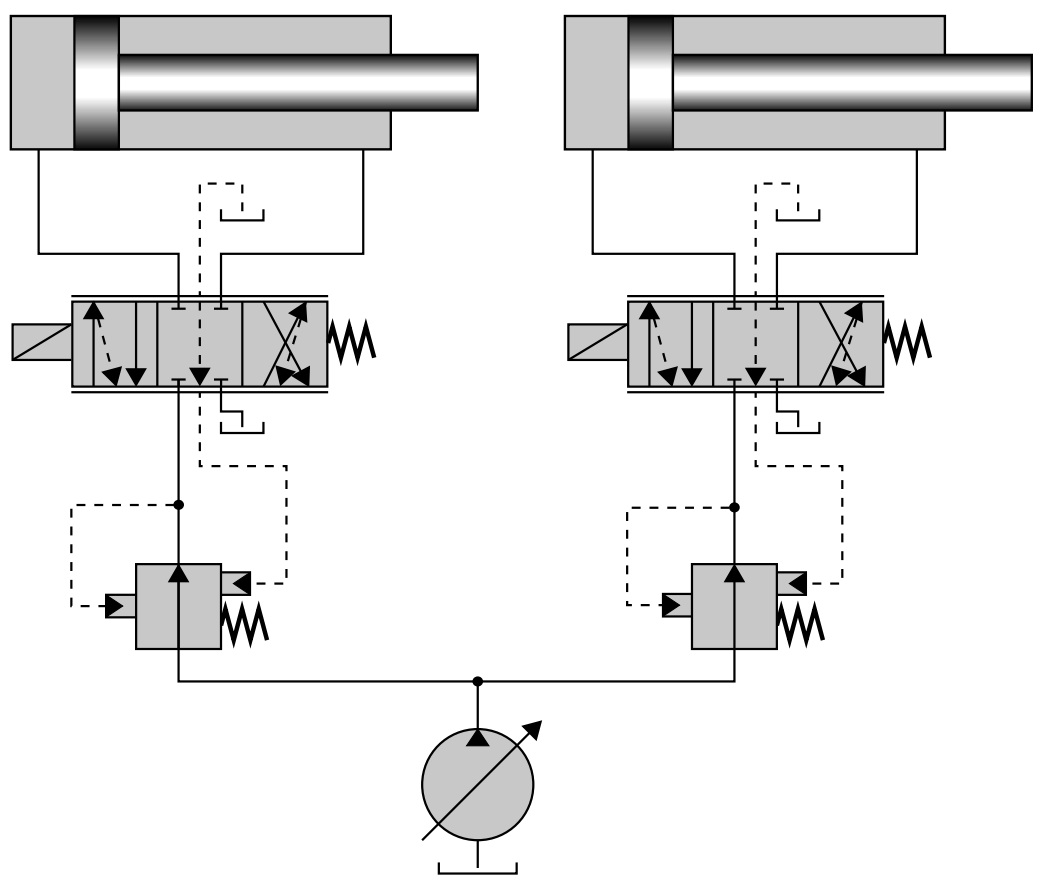

Figure 3.4 Simplified schematic of a flow control system using traditional pressure compensators. The system can also be realized with traditional compensators placed downstream of the directional valves.

The pump flow is too high Both compensator spools will close more and the pump pressure will increase until the system's main relief valve opens. The throttle losses will be huge and the system will emerge as a constant pressure system.

The reason for this is that both the pump and the valves control the absolute flow, resulting in an over-determined flow situation. A great deal of research solving this flow matching problem has been presented. [Djurovic and Helduser, 2004] introduced a position sensor placed on the directional valve. This gives precise knowledge of the flow expected by the valve. It is also possible to equip the compensator with a position sensor [Djurovic, Helduser, and Keuper, 2004]. If no compensator is close to fully opened, the pump flow is too high. If the pump flow is too low, the compensator at the highest load would be completely opened. A bleed-off valve to tank is proposed by several authors, see for example [Djurovic, Keuper, et al., 2006], [Mettälä et al., 2007] 
and [Cheng, $\mathrm{Xu}$, Liu, et al., 2013]. A small overflow is then acceptable, which could be used in closed-loop control if a position sensor is added. [Fedde and Harms, 2006] discuss the pros and cons of overflow and underflow when using a bleed-off valve. [Grösbrink and Harms, 2009] and [Grösbrink, Baumgarten, et al., 2010] propose a system design where the pump is pressure controlled for low pump flows and flow controlled for high flow rates. It is also possible to shift from flow control to pressure control in case of an undesirable pressure build-up [Xu, Liu, et al., 2012] [Xu, Cheng, et al., 2015]. A review of solutions to the flow matching problem in flow control systems using traditional compensators has been made by [Djurovic, 2007]. A novel approach to solve this problem is proposed in this thesis, see section 6.2.

\subsubsection{Flow Control using Flow Sharing Compensators}

There are alternatives to address this flow matching problem without adding additional components or sensors to the system. The key is to implicate the highest load pressure into the compensator and thus obtain the flow sharing behaviour described in section 3.1.2. The entire pump flow will then be distributed relative to all active functions and there will be no flow matching issues, see figure 3.5. Instead of controlling the flow, the valves will serve as flow dividers. This has been studied in, for example, [Latour, 2006] and [Finzel and Helduser, 2008a].

Using a flow controlled pump in combination with flow sharing pressure compensators opens up new possibilities in terms of controlling the directional valves independently of the cylinder velocities. One control approach is to open the valve section at the load with the highest flow demand to its maximum, see [Finzel and Helduser, 2008b], paper [VII] and [Cheng, $\mathrm{Xu}$, and Yang, 2014]. Other active functions must always be opened in proportion to its flow request. This control approach will minimize the pressure drop across the directional valves and thus save energy, see figure 3.6. This is further discussed in chapter 4 .

Another control approach would be to use the valves to increase the system damping. There is an optimal valve opening where the damping is maximized. For example, when a function is oscillating the valve opening could be reduced temporarily in order to dampen the oscillations. When no oscillations are present, a more energy-efficient control strategy can be used. This is further discussed in section 5.3.1. 


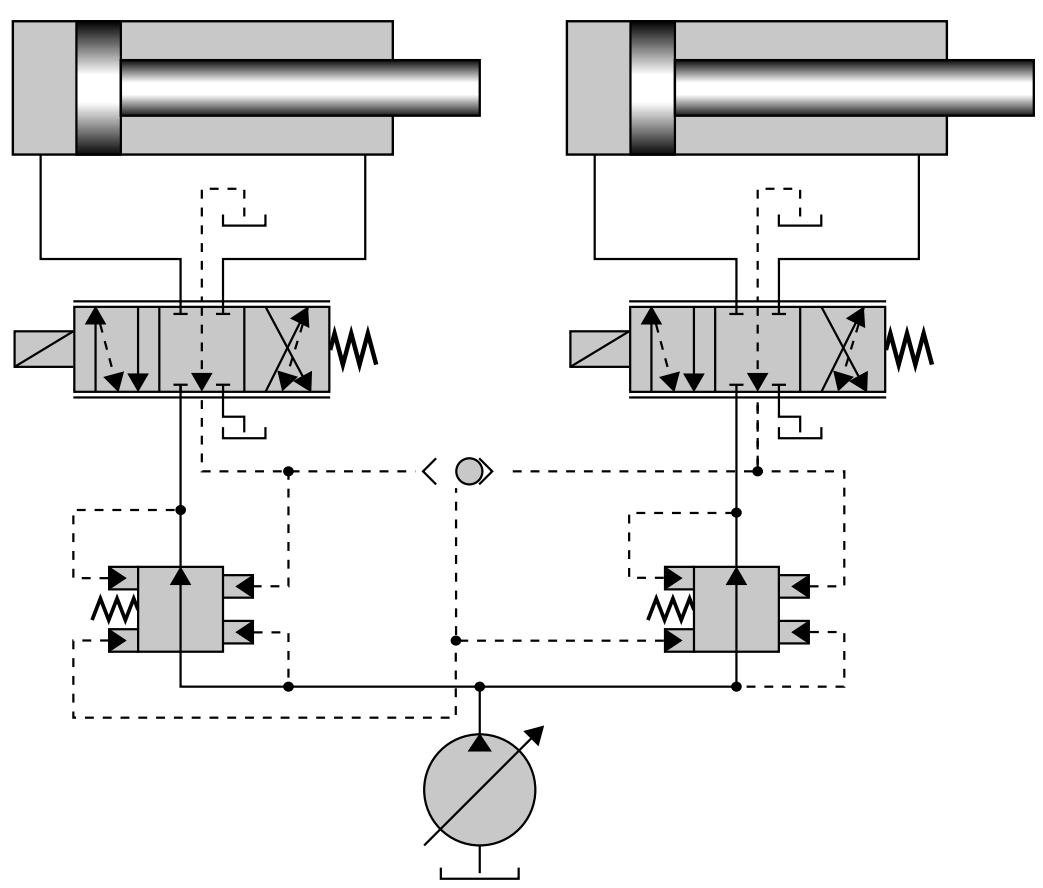

Figure 3.5 Simplified schematic of a flow control system using flow sharing pressure compensators. The system can also be realized with flow sharing compensators placed downstream of the directional valves.

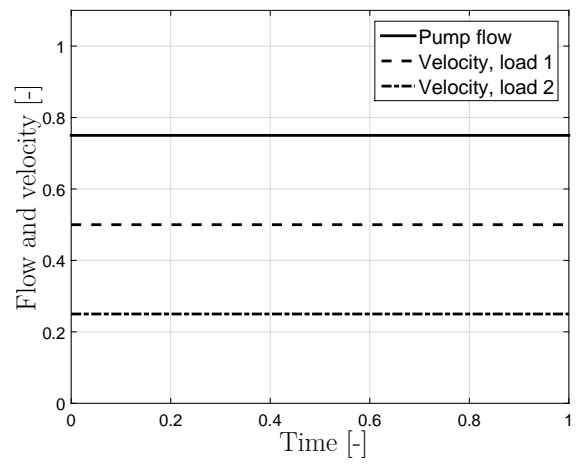

(a) The pump flow and both actuator velocities are constant.

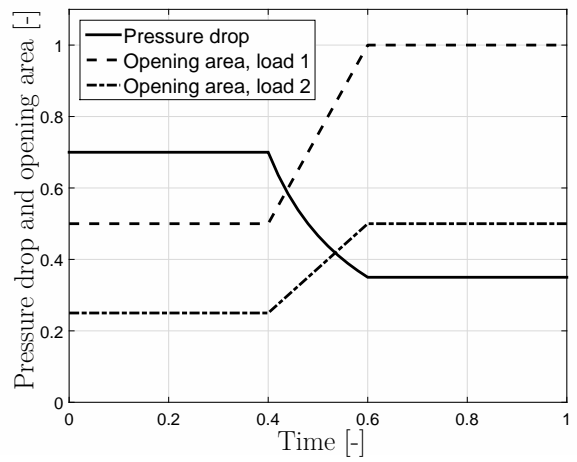

(b) The pressure drop across the directional valves will decrease when the opening areas are increased.

Figure 3.6 Flow sharing system characteristics. Both directional valve opening areas are increased without affecting the actuator velocities. The pressure drop across both directional valves will decrease. 


\section{4 \\ Energy Efficiency Analysis}

The energy efficiency of flow control systems is similar to that of load sensing systems. The pump pressure is adjusted according to the highest load and high losses might occur when loads with different pressure demands are operated simultaneously. However, instead of a prescribed pressure margin, as in load sensing systems, the pressure drop between pump and load is given by the resistance in the hoses and in the valves. Furthermore, it is also possible to lower the pressure drop across the directional valves by opening the valve at the load with the highest flow demand to its maximum.

In load sensing systems, the pump pressure margin is set to overcome the losses in the pump hose, the compensator and the directional valve. These losses are system-dependent and will change with internal and external conditions such as temperature, oil properties, hose length, etc. The pressure margin is set according to the worst case to ensure it is high enough at all operating points.

The pressure drop between pump and load can be divided into three different losses:

Losses between pump and valve There will be a pressure drop between the pump and the valve. The magnitude will depend on the internal and external properties mentioned above, but most importantly the flow rate. A simplified model is that the losses increase with the square of the flow rate. 
Losses across the compensator There will be a pressure drop across the compensator. High losses occur if the supply pressure is much higher than the load pressure. This is the case at partial loading conditions. The smallest possible loss occurs when the compensator is fully opened. In this case, the required pressure drop increases with the square of the flow rate.

Losses across the directional valve Typically, the compensator ensures that the pressure drop across the directional valve is constant. However, the smallest possible pressure drop occurs if the valve is fully open. The pressure drop will then follow the flow equation, similar to the compensator pressure drop.

In figure 4.1a, these three different losses are shown. If the pressure margin is set perfectly, there will be no unnecessary losses at maximum flow rate in load sensing systems. However, at lower flow rates, unnecessary losses will occur. In flow control systems, these losses will be eliminated since the pump pressure is set by the resistance in the hose and the valve.

It is possible to further reduce the losses in flow control systems. This is done by opening the valve section with the highest flow demand to its

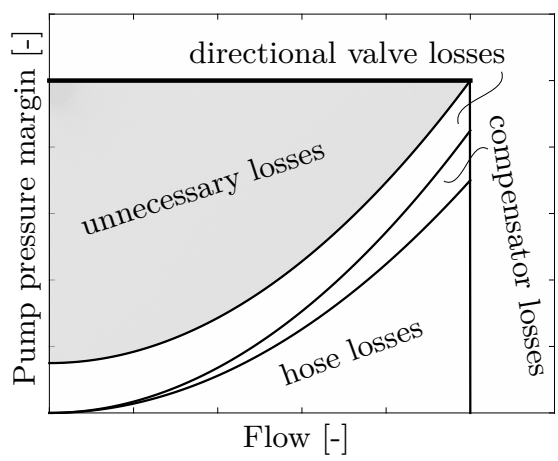

(a) The pump pressure margin is fixed in load sensing systems. Therefore, unnecessary losses occur at lower flow rates.

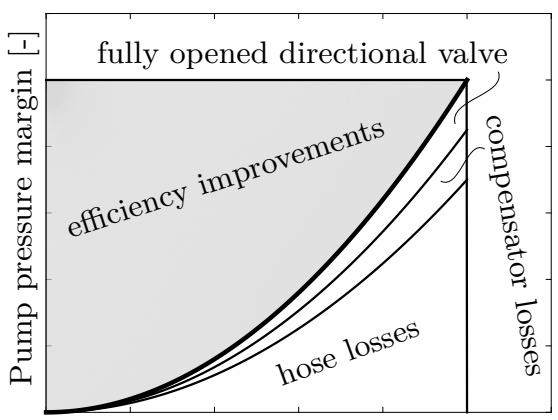

Flow [-]

(b) The pump pressure margin is given by the system resistances in flow control systems. Efficiency improvements are therefore possible.

Figure 4.1 Classification of the losses between pump and load. Three different losses occur: hose, compensator and directional valve losses. At lower flow rates, unnecessary losses occur in load sensing systems. No unnecessary losses occur in flow control systems. 
maximum, in which case the pressure drop across the directional valve is minimized and additional energy savings are possible, see figure $4.1 \mathrm{~b}$.

A flow control system without pressure compensators would increase efficiency even further. In this case, the valve section at the highest load might be opened completely. However, its functionality requires closedloop control and is therefore sensor dependent [Jongebloed et al., 2004].

As can be seen in figure 4.1, the two system layouts have the same efficiency at maximum flow rate if the pump pressure margin is set perfectly in the load sensing system. Flow control systems have higher efficiency for smaller flow rates. However, it is important to consider the power losses rather than the pressure losses. For low flow rates, the power loss will be small even for high pressure drops. Figure 4.2 shows the power saving opportunities for flow control systems. The largest power savings occur in the medium flow rate area. If the directional valve is opened completely, even more power can be saved.

Flow control systems have no unnecessary losses for the highest load. All losses that occur are necessary and limited by, for example, the diameter of the hoses and the maximum opening areas in the valve. However, flow control systems still have high losses under partial loading conditions. To increase efficiency even further, individual metering valves or additional hydraulic machines are required.

A flow control system with two hydraulic pumps has been studied

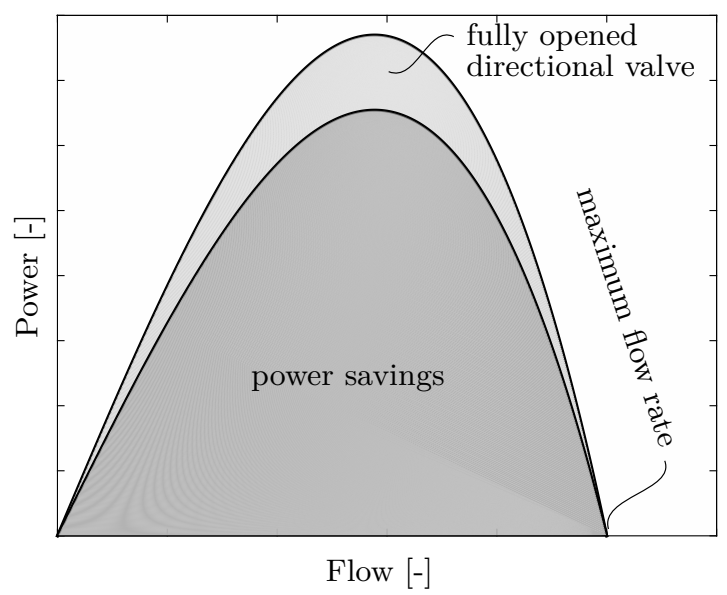

Figure 4.2 Power savings in flow control systems compared to load sensing systems. More power can be saved if the directional valve is completely opened. No power is saved at maximum flow rate. 
in [Finzel et al., 2009] and [Finzel et al., 2010]. The aim is to reduce the losses under partial loading conditions without increasing the total installed displacement. This is achieved by connecting the two pumps when high flow rates are required by one load. Connecting several pumps at high flow rates is a common solution for simpler systems, for example, in excavators. 


\section{Dynamic Analysis}

The dynamic analyses in this thesis were made to show the fundamental differences between load sensing systems and flow control systems. Linear models are used and different types of compensators are considered in the analyse. The only difference between the load sensing system model and the flow control system model is the absence of feedback to the pump controller in the flow control system, see figures 5.1 and 5.2. Nevertheless, there are fundamental dynamic differences between the two system layouts.

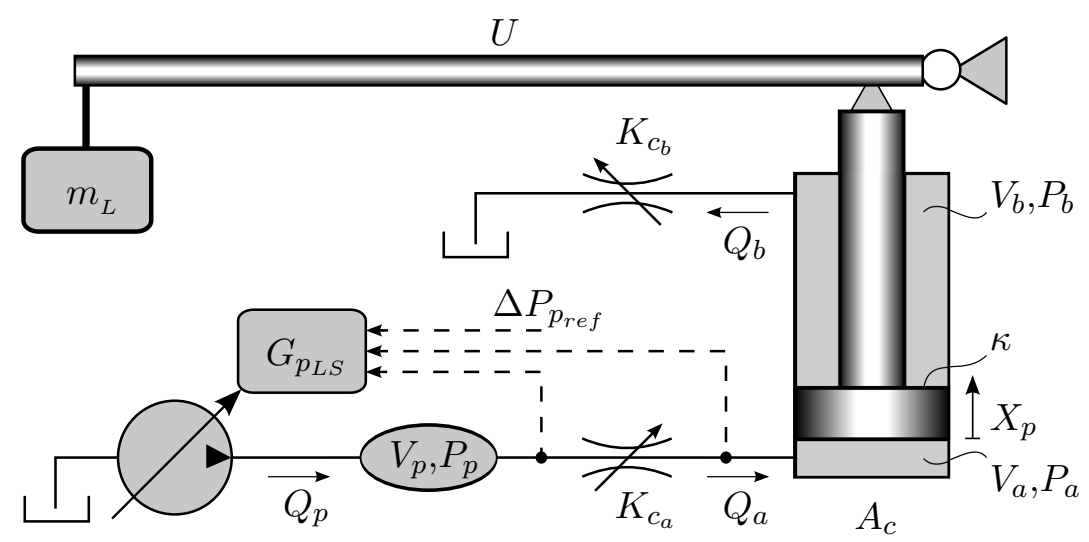

Figure 5.1 Dynamic load sensing system model. 


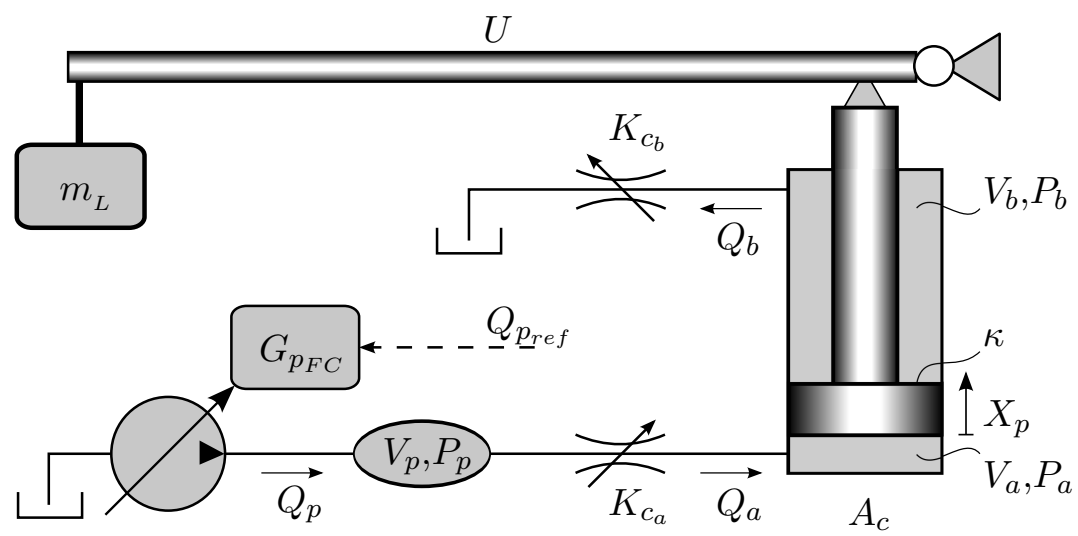

Figure 5.2 Dynamic flow control system model.

\subsection{Mathematical Model}

A linear mathematical model is constructed to perform the dynamic analyses. The derivation of the equations is shown in [Merritt, 1967].

The pump controller can be described in two different ways. In load sensing systems, the controller consists of a pressure controlled valve that controls the displacement piston. If the pressure balance, $\Delta P_{p}=$ $P_{p}-P_{a}$, is disturbed, the valve is displaced and the pump setting is then proportional to the integrated valve flow. Here, the pump is modelled as a pure inductance, see equation (5.1) [Palmberg et al., 1985].

$$
G_{p_{L S}}=\frac{Q_{p}}{\Delta P_{p_{r e f}}-\Delta P_{p}}=\frac{1}{L_{p} s}
$$

The pump controller in flow control systems controls the displacement, and thereby the flow, directly instead of maintaining a certain pressure margin above the highest load pressure. Such a pump controller has no external feedback from the system, similar to the load sensing feedback. Instead, it has an internal feedback measuring the actual flow rate. If the flow balance, $Q_{p_{r e f}}-Q_{p}$ is disturbed, the valve is displaced and the pump setting is proportional to the integrated valve flow. Here, the transfer function describing the displacement controlled pump dynamics is called $G_{p_{F C}}$, see equation (5.2).

$$
G_{p_{F C}}=\frac{Q_{p}}{Q_{p_{r e f}}}
$$


The continuity equation of the pump volume yields the transfer function in equation (5.3).

$$
H_{s}=\frac{P_{p}}{Q_{p}-Q_{a}}=\frac{\beta_{e}}{V_{p} s}
$$

The model for the inlet orifice in the directional valve will be different depending on the design of the compensator. A non-compensated valve will have a flow-pressure dependency according to equation (5.4). In this analysis, the valve is considered to be much faster than the rest of the system. The valve dynamics are therefore ignored. The dynamics of pressure compensated valves have been studied in, for example, [Pettersson et al., 1996] and [Wu et al., 2007].

$$
G_{v_{a}}=\frac{Q_{a}}{P_{p}-P_{a}}=K_{c_{a}}
$$

A traditionally compensated valve will have no flow-pressure dependency since the pressure drop across the directional valve is constant, see equation (5.5).

$$
G_{v_{a}}=\frac{Q_{a}}{P_{p}-P_{a}}=0
$$

A flow sharing pressure compensated valve will have a flow-pressure dependency, similar to a non-compensated valve, for the highest load. Lighter loads have no flow-pressure dependency, like traditional compensated valves. However, lighter loads will be disturbed by the highest load due to cross-coupling of the highest load pressure to all compensators [Lantto, 1994].

$$
\begin{array}{r}
G_{v_{a}}=\frac{Q_{a}}{P_{p}-P_{a}}=K_{c_{a}}, \quad \forall P_{a}=P_{a_{\max }} \\
G_{v_{a}}=\frac{Q_{a}}{P_{p}-P_{a}}=0, \quad \forall P_{a}<P_{a_{\max }} \\
G_{v e_{a}}=\frac{Q_{a}}{P_{p}-P_{a_{\max }}}=K_{c_{a}}, \quad \forall P_{a}<P_{a_{\max }}
\end{array}
$$

A detailed investigation of valve models using different compensation techniques can be found in [Lantto, 1994] and paper [II].

A mass load with a gear ratio is considered to act on a cylinder. The continuity equation for the cylinder chambers together with the force 
equilibrium for the piston is shown in equations (5.7), (5.8) and (5.9).

$$
\begin{aligned}
& Q_{a}=\frac{V_{a}}{\beta_{e}} s P_{a}+A_{c} s X_{p} \\
& U^{2} m_{L} s^{2} X_{p}+B_{p} s X_{p}=A_{c} P_{a}-\kappa A_{c} P_{b} \\
& \kappa A_{c} s X_{p}-Q_{b}=\frac{V_{b}}{\beta_{e}} s P_{b}
\end{aligned}
$$

It is also possible to describe a load which consists of a hydraulic motor by similar equations, see paper [II].

The outlet orifice in the directional valve is considered to have a flowpressure dependency according to equation (5.10).

$$
G_{v_{b}}=\frac{Q_{b}}{P_{b}}=K_{c_{b}}
$$

\subsection{Pump Stability}

Due to the absence of load pressure feedback to the pump controller in flow control systems, there is a fundamental dynamic difference between load sensing and flow control systems. To show this, the mathematical model in section 5.1 can be simplified. A flow-pressure dependency at the inlet side of the valve is assumed and the outlet orifice is ignored. The simplifications will not influence the fundamental differences but are important to bear in mind when making other dynamic analyses.

A transfer function from inlet flow to pressure in the cylinder can be derived using equations (5.7) and (5.8). Ignoring the outlet orifice results in a constant pressure on the piston rod side.

$$
Z_{L}=\frac{P_{a}}{Q_{a}}=\frac{U^{2} m_{L} s+B_{p}}{\frac{V_{a}}{\beta_{e}} U^{2} m_{L} s^{2}+\frac{V_{a}}{\beta_{e}} B_{p} s+A_{c}^{2}}
$$

\subsubsection{Load Sensing Systems}

The dynamic behaviour of load sensing systems can be described by equations (5.1), (5.3), (5.4) and (5.11). By reducing the block diagram in figure 5.3a, the open-loop transfer function from desired pump pressure margin, $\Delta P_{p_{r e f}}$, to actual pressure difference, $\Delta P_{p}=P_{p}-P_{a}$, can be derived according to equation (5.12). A complete investigation of load sensing systems and their dynamic properties, including pump controllers, can be found in [Krus, 1988]. 


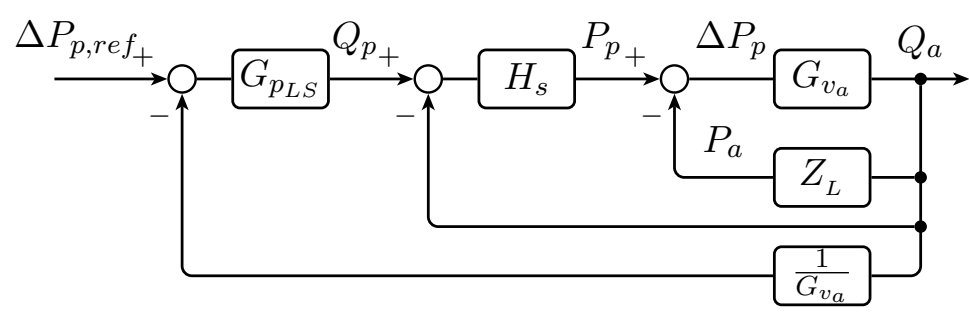

(a) Block diagram of a load sensing system derived from the transfer functions (5.1) (pump controller), (5.3) (pump volume), (5.4) (inlet valve) and (5.11) (load).

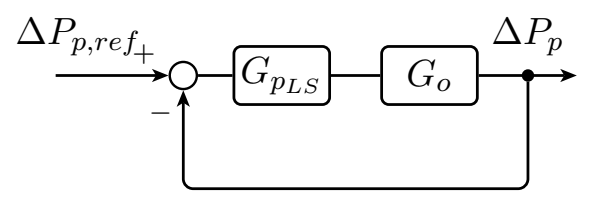

(b) Rearranged block diagram with the loop gain $G_{p_{L S}} G_{o}$.

Figure 5.3 Linear model of a load sensing system.

$$
G_{p_{L S}} G_{o}=G_{p_{L S}} \frac{H_{s}}{1+G_{v_{a}}\left(Z_{L}+H_{s}\right)}
$$

By closing the control loop, the pump controller, $G_{p_{L S}}$, is a part of the loop gain, $G_{p_{L S}} G_{o}$, as shown in figure 5.3b. To achieve a stable system, the loop gain must be kept lower than unity when the phase crosses $-180^{\circ}$. On the other hand, it would be feasible to increase the gain of the pump and its controller to achieve a system that meets the response requirements. To achieve a system with desired response, the gain of the pump controller is increased, but at the same time the system is approaching its stability limit. One should bear in mind that stability at one operational point will not guarantee stability at another, see figure 5.4.

\subsubsection{Flow Control Systems}

The dynamic behaviour of flow control systems can be described by equations (5.2), (5.3), (5.4) and (5.11). This results in almost the same 

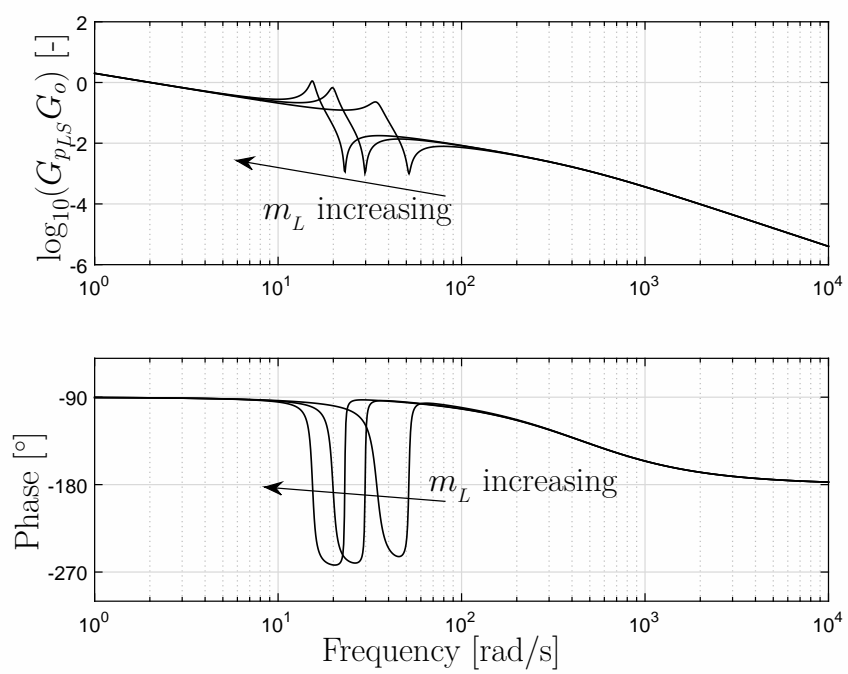

Figure 5.4 Bode plot of the open-loop gain in figure 5.3b, $G_{p_{L S}} G_{o}$.

Table 5.1 Parameter values used in figure 5.4.

\begin{tabular}{lrl}
\hline Parameter & Value & Unity \\
\hline$A_{c}$ & 0.008 & $\mathrm{~m}^{2}$ \\
$B_{p}$ & 10000 & $\mathrm{Ns} / \mathrm{m}$ \\
$V_{a}$ & $4 \cdot 10^{-3}$ & $\mathrm{~m}^{3}$ \\
$V_{p}$ & $5 \cdot 10^{-3}$ & $\mathrm{~m}^{3}$ \\
$K_{c_{a}}$ & $1 \cdot 10^{-9}$ & $\mathrm{~m}^{5} / \mathrm{Ns}$ \\
$L_{p}$ & $5 \cdot 10^{8}$ & $\mathrm{~Pa} \mathrm{~s}^{2} / \mathrm{m}^{3}$ \\
$m_{L}$ & {$[60001200030000]$} & $\mathrm{kg}$ \\
$U$ & 1 & - \\
$\beta_{e}$ & $1 \cdot 10^{9}$ & $\mathrm{~Pa}$ \\
\hline
\end{tabular}

block diagram as in figure 5.3. The only difference is the absence of feedback to the pump controller, see figure 5.5. This results in a fundamental dynamic difference between load sensing systems and flow control systems. Since there is no closed-loop for the pump controller, the stability issues described in section 5.2.1 are eliminated. The pump and its controller can thereby be designed to meet the response requirements without considering system stability. This has been verified by experiments in [Latour, 2006] and [Finzel and Helduser, 2008a]. 


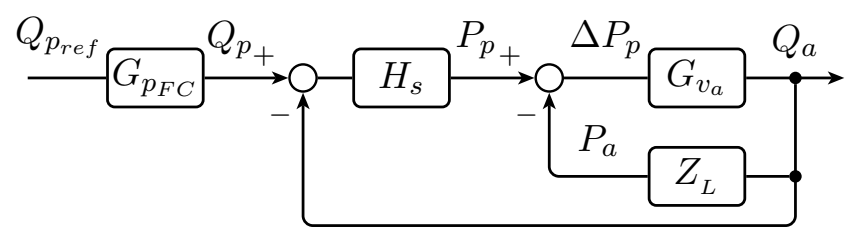

(a) Block diagram of a flow control system derived from the transfer functions (5.2) (pump controller), (5.3) (pump volume), (5.4) (inlet valve) and (5.11) (load).

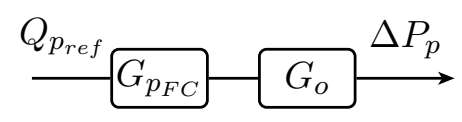

(b) Rearranged block diagram with no feedback present.

Figure 5.5 Linear model of a flow control system.

\subsection{Damping}

Hydraulic systems in themselves are normally poorly damped and need some additional damping from the valves to prevent, or at least reduce, their tendency to oscillate. To obtain damping from a valve, the flow has to increase when the pressure drop across the valve increases and vice versa. Statically, the flow is pressure-independent in flow control systems. The damping contribution from the directional valve is therefore often low.

[Andersson, 1997] gives an overview of the valves' contribution to damping in mobile hydraulic systems. An overview of active oscillation damping of mobile machine structure can be found in [Rahmfeld and Ivantysynova, 2004].

\subsubsection{Active Control of the Inlet Orifice}

In this section, the damping contribution of the inlet orifice in flow control systems is analysed. The cylinder friction and the outlet orifice are ignored to simplify the analysis, see figure 5.6. The inlet valve is assumed to have a flow-pressure dependency, which means that it could be a non-compensated valve or a flow sharing valve at the highest load 


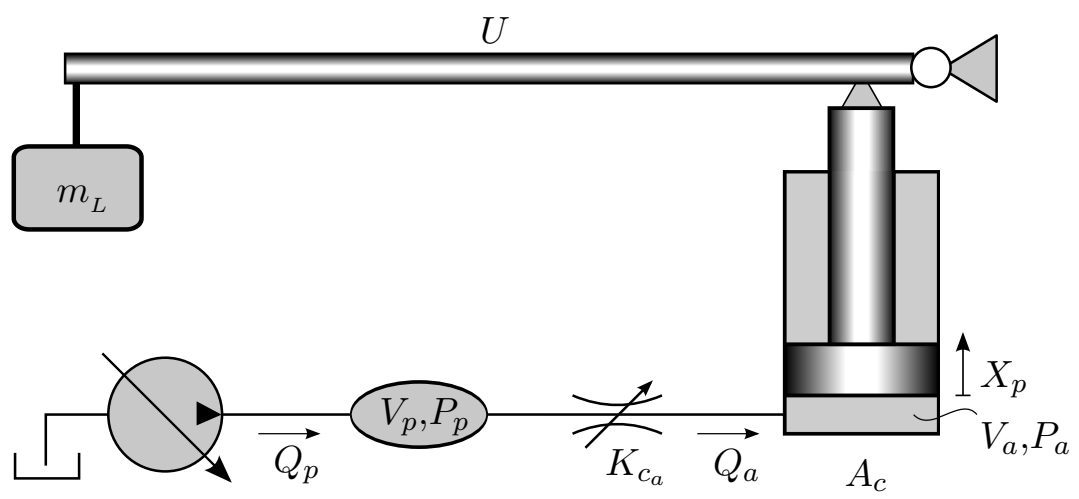

Figure 5.6 Dynamic model of a flow control system with a mass load. The outlet orifice and the cylinder friction have been ignored.

according to equation (5.6).

The system can be described by equations (5.2), (5.3), (5.4) and (5.11). An expression for the flow-pressure coefficient of the inlet orifice that gives the highest damping was derived in paper [II] according to equation (5.13).

$$
K_{c_{a_{o p t}}}=\frac{A_{c}}{\gamma_{i}^{3 / 4}} \sqrt{\frac{V_{p}\left(\gamma_{i}-1\right)}{\beta_{e} U^{2} m_{L}}}
$$

where

$$
\gamma_{i}=1+\frac{V_{p}}{V_{a}}
$$

The maximum damping in the system can be calculated using equation (5.15).

$$
\delta_{h_{\max }}=\frac{1}{2}\left(\sqrt{\gamma_{i}}-1\right)
$$

Equation (5.15) shows that the maximum damping given by the inlet orifice only depends on the value of $\gamma_{i}$, which includes the pump hose volume and the volume at the inlet side of the cylinder according to equation (5.14). To obtain a high damping contribution from the inlet orifice, the pump hose volume should be large compared to the volume on the inlet side of the cylinder. However, this relationship will change during the cylinder stroke. Damping as a function of the inlet orifice opening area for different values of $\gamma_{i}$ is shown in figure 5.7. 


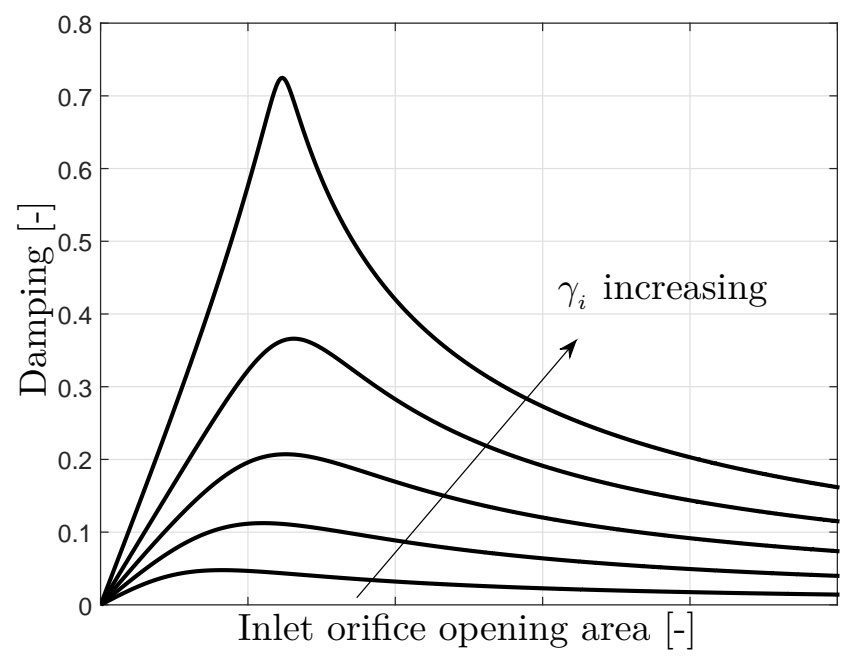

Figure 5.7 System damping as a function of the opening area of the inlet orifice. A small value of $\gamma_{i}$ gives low damping regardless of the opening area. Damping will increase with higher values of $\gamma_{i}$.

To obtain the highest possible damping for a given value of $\gamma_{i}$, the inlet orifice opening area has to be small. At certain points of operation this might result in substantial power losses, see paper [II]. To avoid this, it is possible to use the more energy-efficient control strategy described in section 3.2.2 while no oscillations are present. When damping is required, the valve can temporarily be closed more to reach the peaks in figure 5.7. Finally, when the oscillations have subsided, the energyefficient control strategy can be applied again. This can be done in flow control systems without affecting the cylinder velocities if flow sharing pressure compensators are used.

Theoretically, a flow control system using traditional compensators obtains no damping from the inlet orifice since the flow is independent of pressure changes, see equation (5.5). This is also true for lower loads using flow sharing compensators according to equation (5.6). One way to obtain damping for such loads is to implement active damping, using for example a dynamic load pressure feedback [Paavilainen et al., 2007].

A special case in this analysis is when the inlet orifice opening area approaches infinity. This is the case in valveless systems, which have no orifices at all. As can be seen from figure 5.7, the damping then approaches zero. Consequently, a valveless system is ideally undamped. 


\subsubsection{Design and Control of the Outlet Orifice}

In this section, the damping contribution of the outlet orifice is analysed. The analysis is not limited to flow control systems, but is valid for all pump controller designs. The prerequisite is that the inlet flow can be modelled as a perfect flow source, which is true if the inlet orifice has no flow-pressure dependency, see figure 5.8. This can be realized with, for example, a traditional pressure compensator.

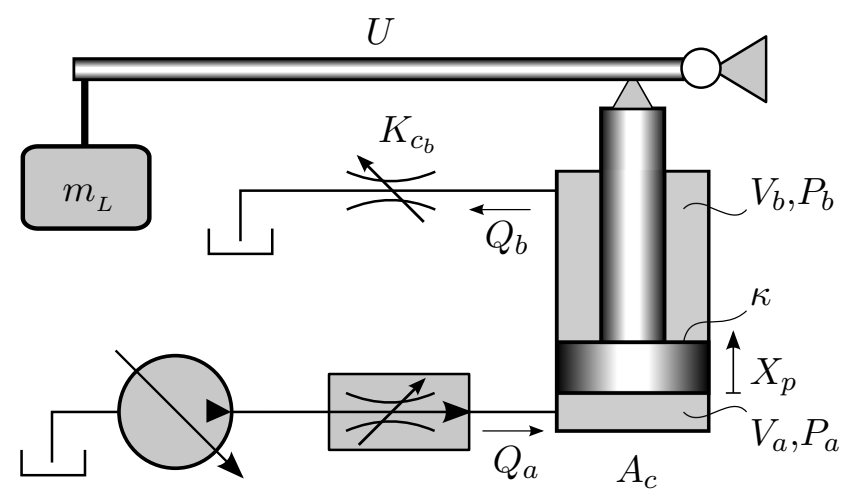

Figure 5.8 Dynamic model of a flow controlled cylinder with a mass load and an outlet orifice. The pump controller can be of any design; it does not affect the analysis.

The system can be described by equations (5.7)-(5.10). Similar to the analysis in section 5.3.1, the viscous friction in the cylinder has been ignored to simplify the analysis. An expression for the flow-pressure coefficient of the outlet orifice that gives the highest damping has been derived in paper [III] according to equation (5.16).

$$
K_{c_{b_{o p t}}}=\kappa A_{c} \sqrt{\frac{V_{b}}{\beta_{e} U^{2} m_{L}\left(\gamma_{o}-1\right)}} \gamma_{o}^{3 / 4}
$$

where

$$
\gamma_{o}=1+\kappa^{2} \frac{V_{a}}{V_{b}}
$$

The maximum damping in the system can be calculated using equation (5.18).

$$
\delta_{h_{\max }}=\frac{1}{2}\left(\sqrt{\gamma_{o}}-1\right)
$$




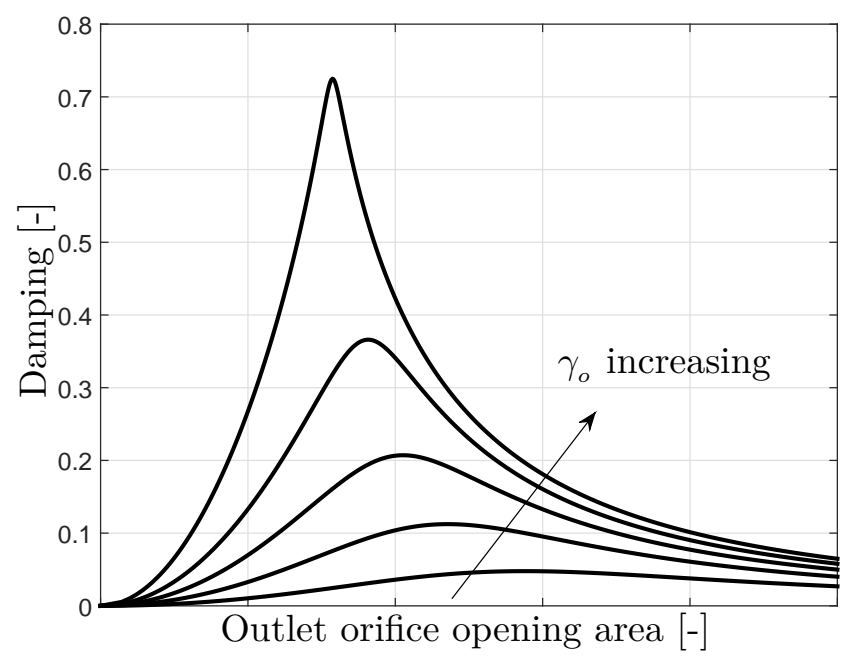

Figure 5.9 System damping as a function of the opening area of the

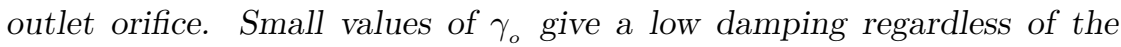
opening area. The damping will increase with higher values of $\gamma_{o}$.

Equation (5.18) shows that the maximum damping of the system depends only on the value of $\gamma_{o}$, which includes the volume at each side of the cylinder and the cylinder area ratio according to equation (5.17). To obtain a high damping contribution from the outlet orifice the volume on the inlet side of the cylinder should be large compared to the volume on the outlet side. This relationship will, however, change during the cylinder stroke. A high value of the cylinder area ratio increases the damping, which means that a symmetrical cylinder gives higher damping than an asymmetrical. The damping as a function of the outlet orifice opening area for different values of $\gamma_{o}$ is shown in figure 5.9.

A valve design that is suggested in paper [III] is to optimize the damping when the piston is at its lower end position. While the piston moves upwards, the damping will increase. If a higher damping is required, it is possible to design the valve with a smaller orifice area. The drawbacks with such a design are, however, that the damping will be slightly lower at the piston's lower end position and that the losses across the outlet orifice will be higher. If lower losses are required, it is possible to design the valve with a larger opening area. However, this is at the expense of a lower damping. There is no point in designing the valve with a too small orifice area. The damping will then be low and the losses high.

If the inlet and outlet orifices were decoupled, as in individual meter- 
ing systems, it would be possible to optimize the damping during the cylinder stroke. While the piston is moving, the outlet orifice could be controlled in order to achieve the highest possible damping. It would also be possible to use a similar control approach to that described in section 5.3.1. When no oscillations are present, the outlet orifice could be fully opened, minimizing the losses. When damping is required, the controller could shift to optimize the damping and temporarily allow higher losses. 


\section{A Flexible Working Hydraulic System}

As described in chapter 2, different hydraulic systems have different system characteristics. In some applications, smooth control with high damping is desired while high energy efficiency and handling capabilities with precise position control are important in others. Different hydraulic systems have therefore been developed for different applications. A flexible system solution using an electrically controlled variable displacement pump is proposed in this chapter. It is possible to realize flow control, load sensing and open-centre, but also a mix of the three systems. Conventional closed-centre spool valves are used, which results in high energy efficiency.

\subsection{Pump Controller}

The pump controller used in the flexible working hydraulic system is shown in figure 6.1. Sensors measure pump pressure, maximum load pressure, shaft speed and pump displacement setting. Input signals from the operator to the electric controller are pressure and flow commands. It is thus possible to control both pressure and flow in closed-loop control. A schematic block diagram of the controller is shown in figure 6.2. In commercial applications, the controller which results in the lowest pump displacement setting is selected. 


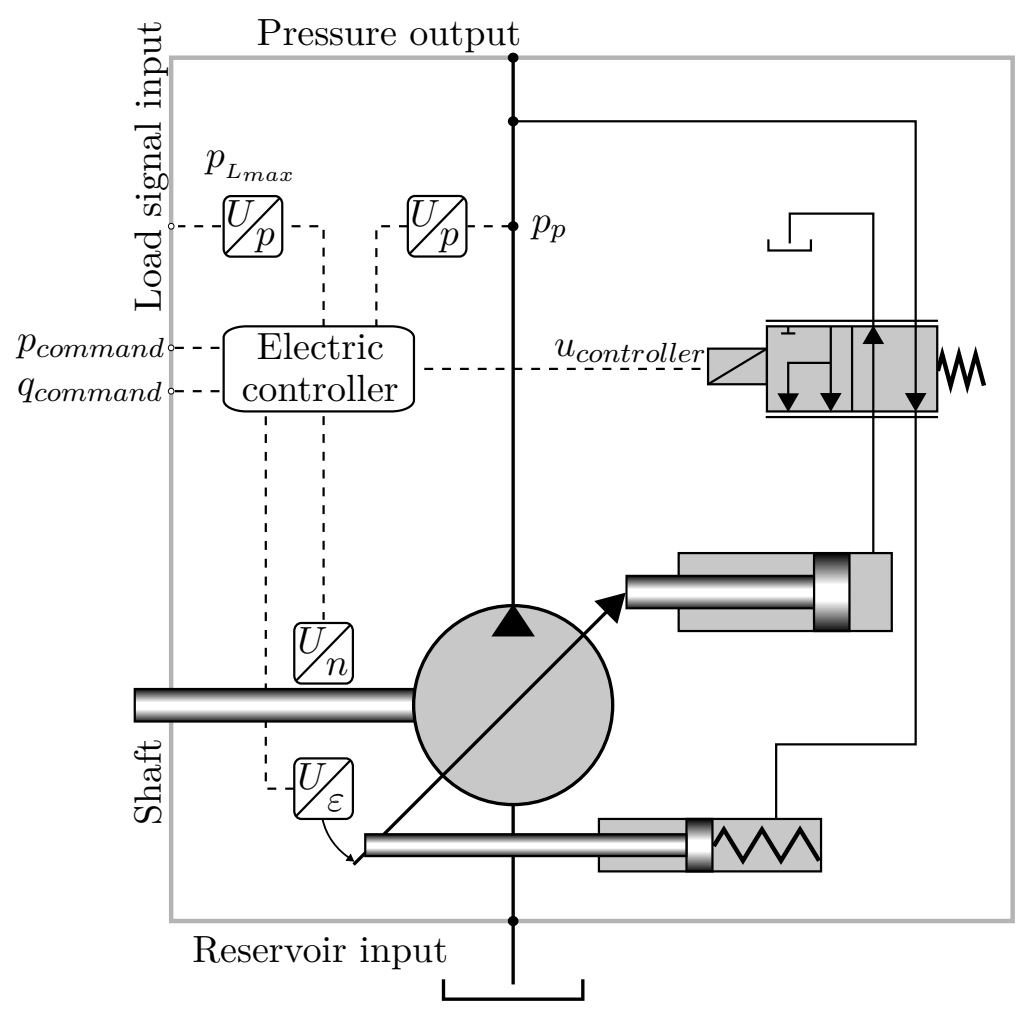

Figure 6.1 Electronic pump controller measuring pump pressure, maximum load pressure, shaft speed and displacement setting [P1 axial piston pump]. Inputs from the operator are pressure and/or flow commands.

\subsection{Combining Flow Control and Load Sensing}

Both load sensing and flow control have their respective pros and cons. One drawback with load sensing is that the pump controller is a part of the loop gain, as shown in section 5.2.1. Improving the pump's response time will decrease the stability margins of the complete system. Flow control has no such issues as explained in section 5.2.2, but other challenges arise instead. For example, it is problematical to combine a flow control pump with traditional pressure compensators, as shown in section 3.2.1. The solution proposed in paper [IV] is to combine pressure and flow control, thereby taking advantage of the respective benefits of the two systems and at the same time avoiding their drawbacks. 


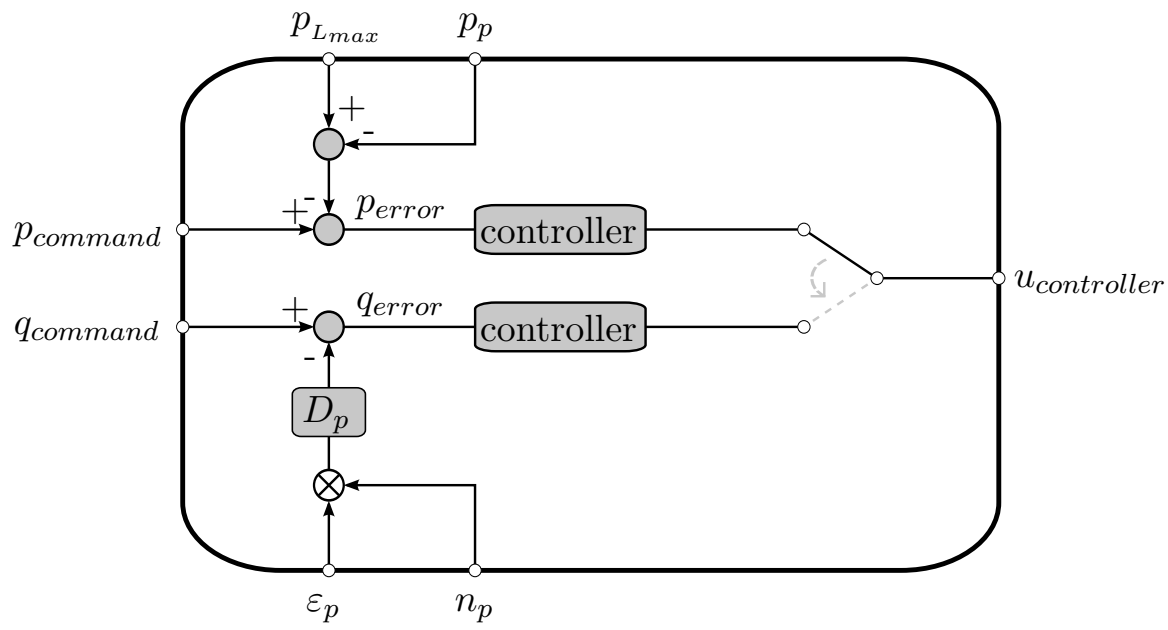

Figure 6.2 Schematic block diagram of the electric controller used in commercial applications. The controller which gives the minimum pump displacement is selected.

Similar ideas have been proposed by other researchers. A pump controller which consists of an electro-hydraulic valve controlling the flow and a hydro-mechanical valve controlling the pressure were studied in [Grösbrink and Harms, 2009] and [Grösbrink, Baumgarten, et al., 2010]. The valves are combined in such a way that the minimum pump displacement of the two controllers is selected. This means that the pump will be flow controlled as long as the pump flow demand is not too high. If the electro-hydraulic controller demands more flow from the pump than the valves can handle, the pressure will rise and the pump controller will automatically be switched to pressure control mode. [Xu, Liu, et al., 2012] and [Xu, Cheng, et al., 2015] have studied a similar approach. The difference is that both flow and pressure control are realized electro-hydraulically. Both approaches use flow control as the primary control mode and pressure control as a safety control mode. Switching controllers might cause stability problems as shown in [Xu, Cheng, et al., 2015]. [Hansen, 2009] and [Hansen et al., 2010] proposed an electronic load sensing design with a pressure controller, in which a feed forward from the joystick command signal was added.

This thesis proposes summarizing the flow controller and the pressure controller in order to obtain influence from both pressure and flow. Furthermore, it is possible for the operator to choose how much influence 


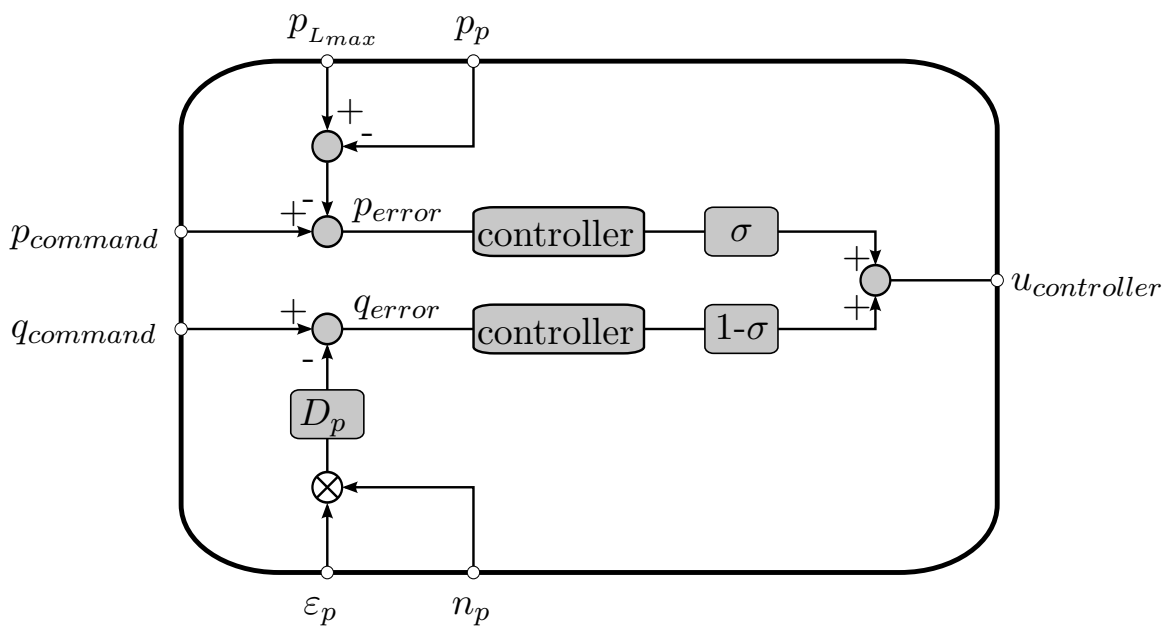

Figure 6.3 Schematic block diagram of the electric controller used in this thesis. The output signal receives influence from both the pressure controller and the flow controller. The parameter $\sigma$ set by the operator determines how much influence should come from the pressure and the flow parts of the controller, respectively.

should come from the pressure and the flow, respectively. This is done using a parameter, $\sigma$, see figure 6.3. $\sigma=1$ results in a pure pressure controller and $\sigma=0$ results in a pure flow controller. $0<\sigma<1$ results in a combination of pressure and flow control. It is thus possible to control the pump continuously from pressure control to flow control.

By using a combination of pressure and flow control, the pump displacement setting is determined partly by the load pressure feedback and partly by the flow command signal. A low load pressure feedback gain can be used to solve the flow matching problem. When too much flow is demanded by the pump and the system pressure rises, the pressure controller will reduce the pump displacement setting, thereby avoiding an undesired pressure build-up. Furthermore, since the pressure controller only has to contribute a small part of the output signal to the displacement control valve, stability margins are gained.

\subsection{Combining Open-centre and Flow Control}

Even though flow control has no stability issues attached to the pump controller, the damping is still often low, as explained in section 5.3. One 
way of increasing the damping is to introduce a load dependency into the system. Open-centre systems have this load dependency in terms of an open-centre channel. The losses, however, are often substantial. Changing to a variable pump but still maintaining open-centre valves improve efficiency. This is done in open-centre load sensing, negative load sensing, negative flow control and positive flow control, see section 2.4. This thesis proposes mimicking the behaviour of a conventional opencentre system by using the electrically controlled pump and closed-centre valves. This will increase energy efficiency further compared to variable pump systems using open-centre valves.

In the proposed solution, the open-centre flow is reproduced virtually by controlling the variable pump. The flow that would go through the open-centre path in a conventional open-centre system is calculated by measuring the pump pressure and having a model of the opening area in the open-centre channel according to equation (6.1) and figure 2.2a.

$$
\begin{aligned}
& q_{\text {virtual }}=C_{q} A_{o c_{1}} \sqrt{\frac{2}{\rho}\left(p_{p}-p_{o c_{1}}\right)}=\ldots=C_{q} A_{o c_{n}} \sqrt{\frac{2}{\rho} p_{o c_{n}}} \\
& q_{\text {virtual }}=C_{q} A_{o c_{1}} \sqrt{\frac{2}{\rho} p_{p}\left(1-\frac{\sum_{k=2}^{n} \frac{1}{A_{o c_{k}}^{2}}}{\sum_{k=1}^{n} \frac{1}{A_{o c_{k}}^{2}}}\right)}
\end{aligned}
$$

The virtual flow through the open-centre path is then subtracted from the maximum flow rate of the pump and the result is the command flow sent to the pump controller, see figure 6.4.

When no valve is activated, the reference flow will be zero. That can be compared with all flow going through the open-centre channel. Activating a valve will decrease the opening area of the virtual open-centre channel, thus allowing a small flow to be sent by the pump, increasing the pump pressure. At a certain pressure level, the reference flow will find its equilibrium, only compensating for its own leakage. Activating the valve more will continue to increase the pressure until the pump pressure becomes higher than the load pressure. There will then be a flow to the load. Increasing the spool stroke further will decrease the opening area in the virtual open-centre channel, which means increased flow from the pump. When the valve is completely opened, the 


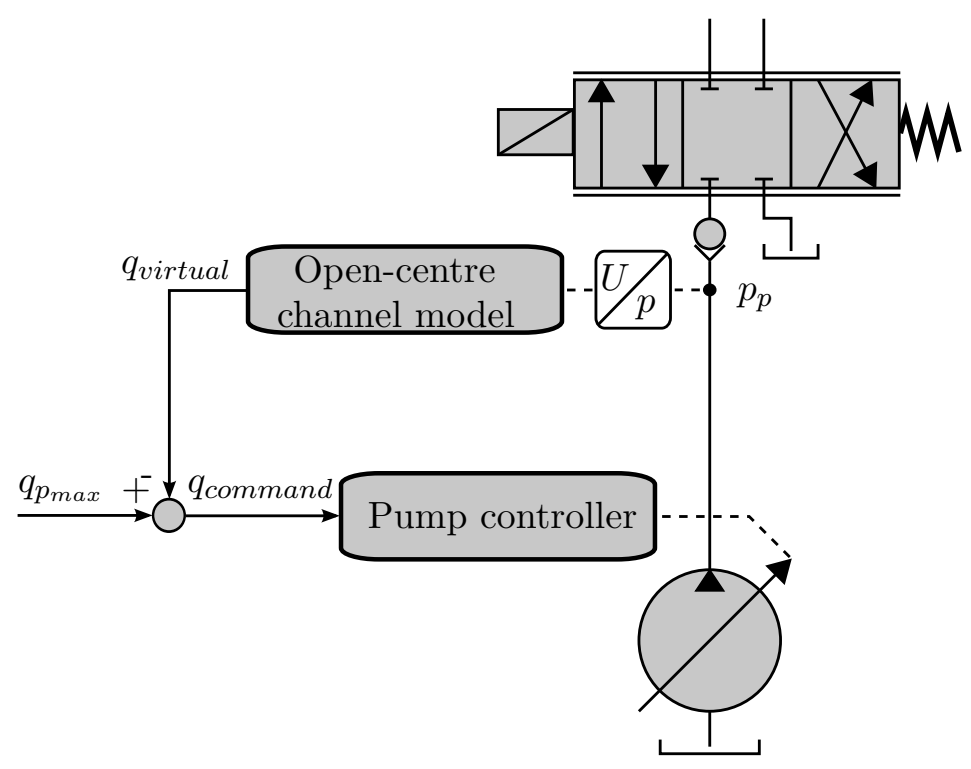

Figure 6.4 Open-centre mode for the proposed system. The virtual flow going through the open-centre channel is calculated and then subtracted from the maximum flow rate of the pump, resulting in a flow command signal sent to the electronic pump controller.

pump will be at maximum displacement, sending all flow to the load. A conventional open-centre system has exactly the same working principle, although control is accomplished hydraulically instead of electrically, see paper $[\mathrm{V}]$.

Since electronic control is used, it is possible to have an arbitrary model of the virtual open-centre channel. For example, it would be possible to continuously decrease it in order to reduce the load dependency. Here, it is proposed to have a parameter, $\xi$, which is a multiplication coefficient on the virtual flow. At the same time, $\xi$ will also change the input signal to the system, see figure 6.5. Instead of being the maximum flow rate, as in figure 6.4 , the input signal will be dependent on the joystick command signals from the operator. The extreme case is when no load dependency exists at all, $\xi=0$, resulting in a flow control system. By changing the value of $\xi$, it is possible to realize a system with opencentre characteristics, a flow control system or something in-between.

A similar commercial system design is the [VBO system] from Bosch Rexroth. However, it does not have the possibility to tune the load sensitivity online. Another similar solution has been patented by 


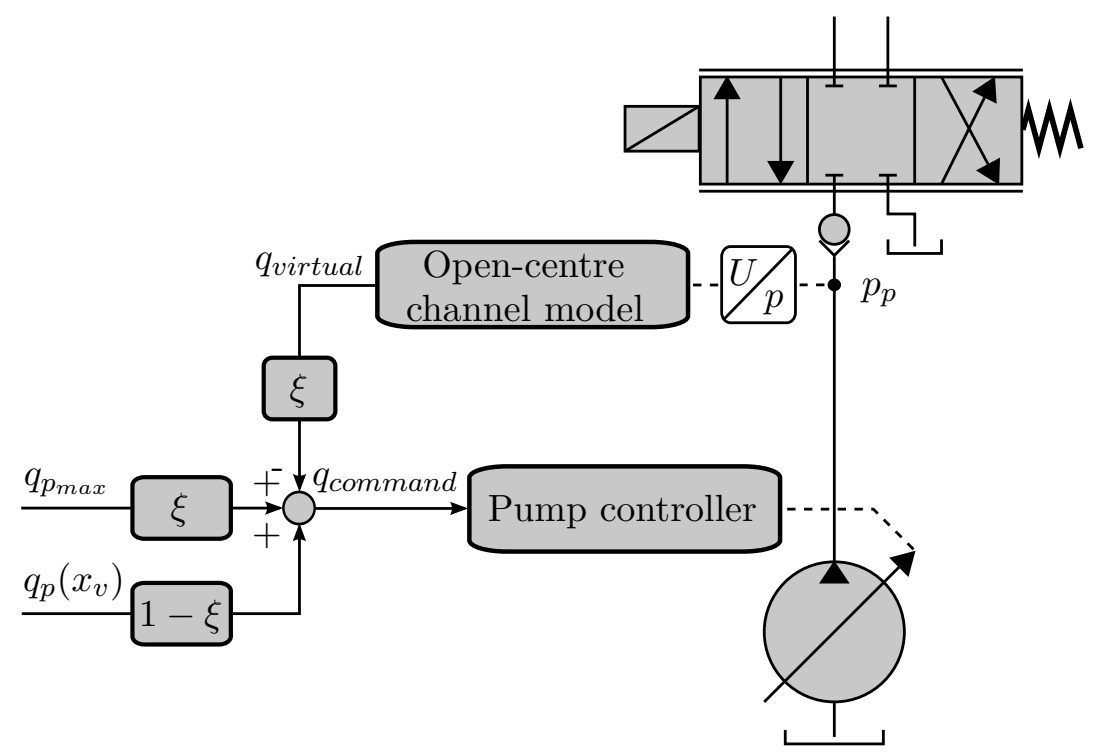

Figure 6.5 Proposed system solution using a flow controlled pump. $\xi=1$ results in open-centre mode, $\xi=0$ results in flow control mode and $0<\xi<1$ results in something in-between.

[Filla, 2014]. A conventional load sensing pump is used and the directional valves are actively controlled in order to achieve open-centre characteristics.

\subsection{Combining Load Sensing and Open-centre}

In a conventional open-centre system, the operator controls the pump pressure by activating a valve. The pump pressure is determined by the opening area in the open-centre path and the magnitude of the open-centre flow. This thesis proposes actively controlling the pump pressure using the variable pump. The same virtual model of the opening area in the open-centre path as in section 6.3 is used. The virtual flow through the open-centre path is calculated by measuring the current pump displacement setting and rotational speed, see equation (6.2). The pump pressure can then be calculated according to equation (6.3).

$$
q_{\text {virtual }}=q_{p_{\text {max }}}-q_{p}=D_{p} n_{p}\left(1-\varepsilon_{p}\right)
$$




$$
\begin{aligned}
q_{\text {virtual }} & =C_{q} A_{o c_{1}} \sqrt{\frac{2}{\rho}\left(p_{p}-p_{o c_{1}}\right)}=\ldots=C_{q} A_{o c_{n}} \sqrt{\frac{2}{\rho} p_{o c_{n}}} \Leftrightarrow \\
p_{p} & =\frac{\rho q_{v i r t u a l}^{2}}{2 C_{q}^{2}}\left(\sum_{k=1}^{n} \frac{1}{A_{o c_{k}}^{2}}\right)
\end{aligned}
$$

When no valve is activated, the reference pump pressure will be close to zero. This is the case when all flow is going through the open-centre path in a conventional open-centre system. Activating a valve will decrease the opening area of the virtual open-centre channel, which will increase the reference pump pressure. At a certain pressure level, equilibrium will be found and the pump will only compensate for its own leakage. The pump displacement setting will then be close to zero, which means that all flow is still going through the open-centre channel. Activating the valve more will continue to increase the pressure until the pump pressure becomes higher than the load pressure. There will then be a flow to the load and the pump displacement setting will increase to maintain the pressure. This reduces the virtual open-centre flow according to equation (6.2). Increasing the spool stroke further will decrease the opening area in the virtual open-centre channel and decrease the virtual open-centre flow, allowing more flow to the load. When the valve is completely opened, the pump will be at maximum displacement, sending all flow to the load.

Similar to section 6.3, it is possible to reduce the load pressure dependency. This is done by the same parameter, $\xi$, which in this case will change the reference pump pressure. Instead of calculating the reference pump pressure according to equation (6.3), it will also be influenced by the maximum load pressure and an additional load pressure margin, see figure 6.6. The extreme case is when no load dependency exists at all, $\xi=0$, resulting in a load sensing system. By changing the value of $\xi$, it is possible to realize a system with open-centre characteristics, a load sensing system or something in-between.

A similar commercial system design is the $3 \mathrm{G}$ valve from Nordhydraulic [Andersson, 2013]. However, it does not have the possibility to tune the load sensitivity online and a small excess flow is needed for the functionality. Differences between the $3 \mathrm{G}$ valve and the solution proposed in this thesis are that system control is accomplished purely hydraulically and that it is possible to include compensators, which eliminates load interference issues. 


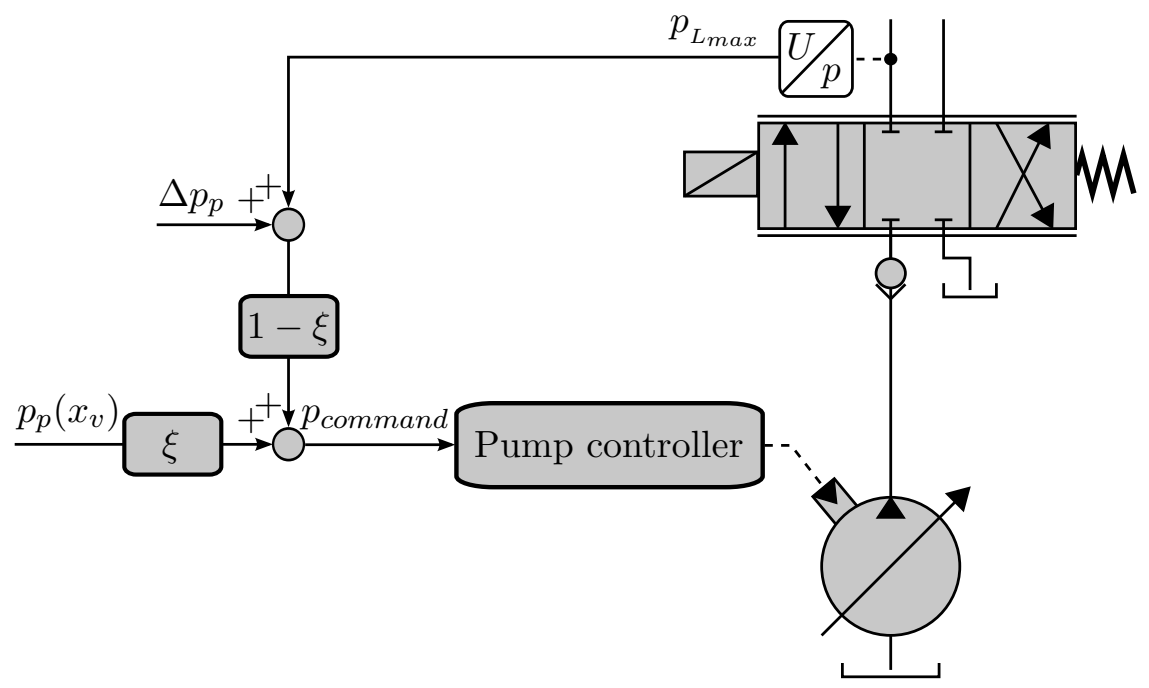

Figure 6.6 Proposed system solution using a pressure controlled pump. $\xi=1$ results in open-centre mode, $\xi=0$ results in load sensing control mode and $0<\xi<1$ results in something in-between.

\subsection{Complete System Solution}

In sections $6.2,6.3$ and 6.4 , three different system solutions have been proposed. All use the electronically controlled pump described in section 6.1. In this section, the three solutions are combined in order to realize a flexible and energy-efficient working hydraulic system.

In the complete system solution, the parameter $\sigma$ determines if the pump should be pressure controlled, flow controlled or something inbetween and the parameter $\xi$ sets the level of load dependency. Figure 6.7 shows the complete block diagram from input signals to dis-

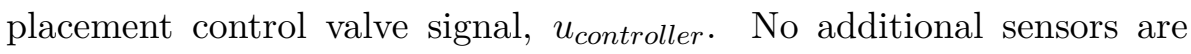
needed, only those available for the electronic pump controller. With the complete system solution, it is possible to realize a load sensing system, a flow control system, an open-centre system or something inbetween, see figure 6.8. Compared with only having the possibility to choose between the three original systems, this expands the design space and opens up the possibility for optimal control characteristics to fit a specific machine, working cycle, load or operator. 


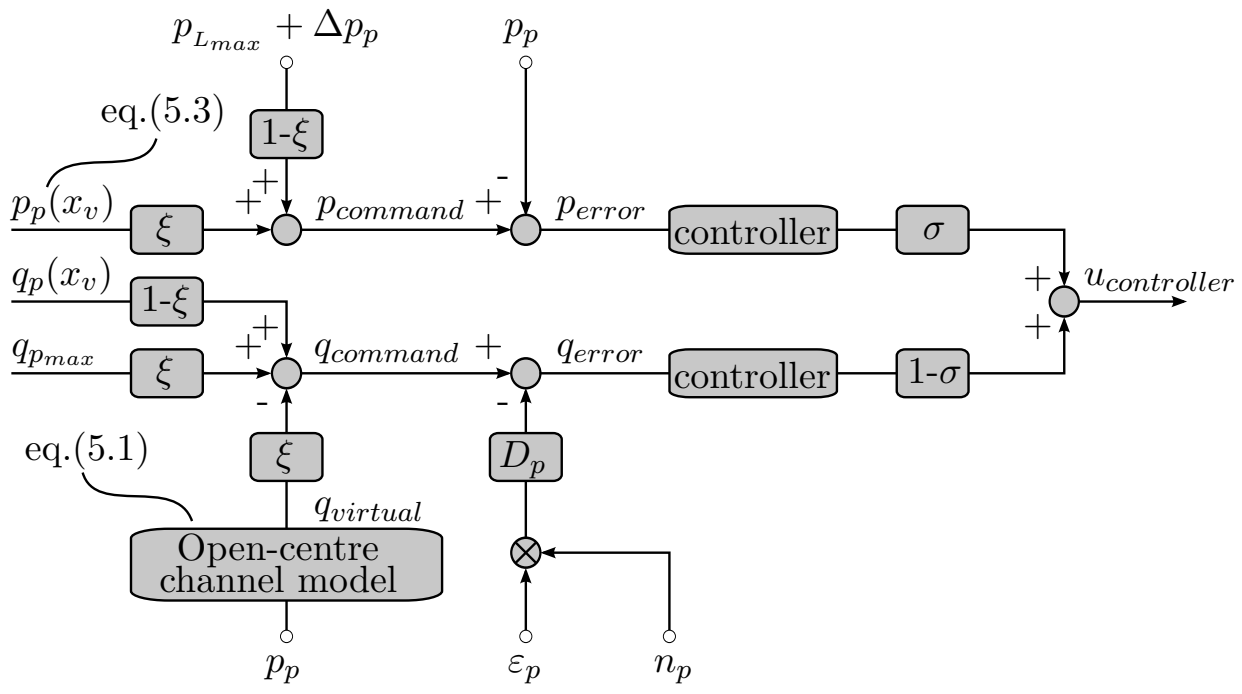

Figure 6.7 Complete block diagram for the proposed system design from input signals to displacement control valve signal, $u_{\text {controller. }} \sigma$ determines if the pump should be pressure controlled, flow controlled or something in-between and $\xi$ sets the level of load dependency.

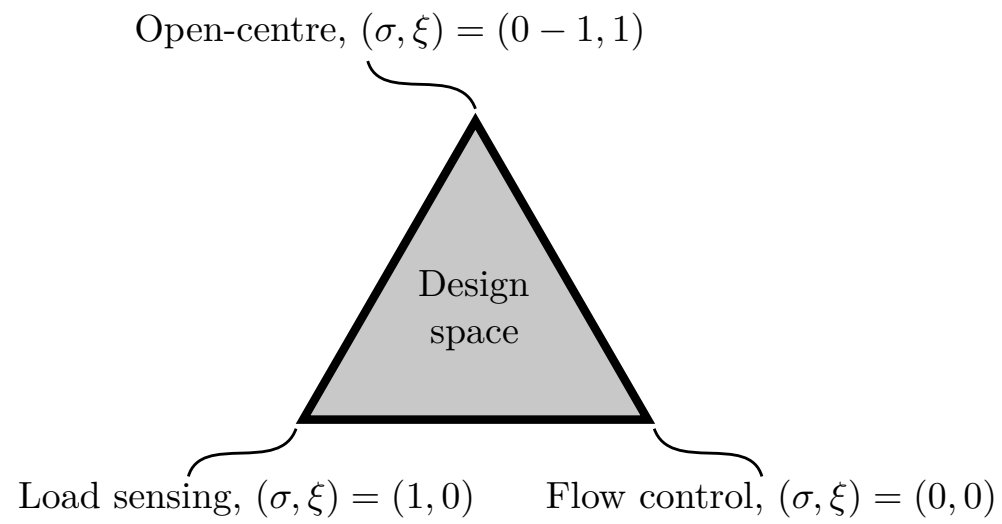

Figure 6.8 Design space for the proposed system design. 


\section{7 \\ Experimental Results}

The energy efficiency improvements described in chapter 4 have been demonstrated using a wheel loader application. Also, the theories concerning the design and control of the outlet orifice described in section 5.3.2 have been validated in a test rig. Furthermore, some features of the flexible hydraulic system described in chapter 6 have been demonstrated using a lorry crane.

\subsection{Energy Efficiency Improvements}

The hardware requirements in flow control systems are similar to load sensing systems. To achieve the same system capacity, a pump size of the same magnitude is used. Only the pump controller needs to be different. Instead of actively maintaining a certain pressure margin above the highest load pressure, the pump displacement is controlled directly from the operator's demand signals. This requires an electrically controlled displacement controller for the pump. However, the load sensing hose to the pump controller can be removed.

Flow control systems use the same type of valves as load sensing systems. Flow sharing pressure compensators are favourable but workarounds with traditional compensators also exist, see section 3.2.1. In some valve designs, a traditional compensator placed upstream of the directional valve can be replaced with its flow sharing equivalent without even replacing the valve housing [L90LS mobile control valve].

Sensors are not required to achieve the desired functionality in flow 
control systems if pressure compensators are used. It would be beneficial, however, to use sensors to detect if the cylinder end stops have been reached [Scherer et al., 2013a] [Scherer et al., 2013b]. If so, the valve could be closed and the pump flow adjusted to avoid unnecessary energy losses.

To verify the energy efficiency improvements in the flow control concept, measurements were performed on a wheel loader application, see figure 7.1. The machine was equipped with a pump that can be operated in both pressure and flow control modes and a valve prepared for use with both traditional and flow sharing compensators, placed upstream of the directional valve.

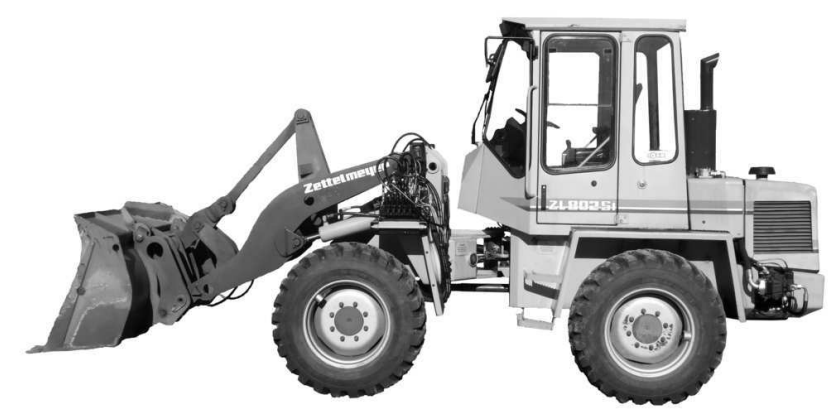

Figure 7.1 The machine used for experiments.

In figure 7.2c, the pump pressure margin for both the load sensing and the flow control systems can be seen. The measurements agree with the theoretical pressure margin shown in figure 4.1. The flow sent by the pump is similar in both systems, see figure 7.2a. It can also be observed from figure $7.2 \mathrm{~b}$ that the pressure is more oscillative in the load sensing system. This is because the pump controller operates in a closed-loop control mode [Krus, 1988].

A short loading cycle [Filla, 2011] has also been performed to compare load sensing and flow control. Only the working hydraulics have been taken into consideration, neither the steering nor the transmission. Figure 7.3a shows the position of the actuators and figure $7.3 \mathrm{~b}$ the energy consumption. The energy consumption was reduced by $14 \%$ for the flow control system in this particular application. This is the same order of magnitude as experiments performed in [Mettälä et al., 2007] and [Finzel and Helduser, 2008a]. 


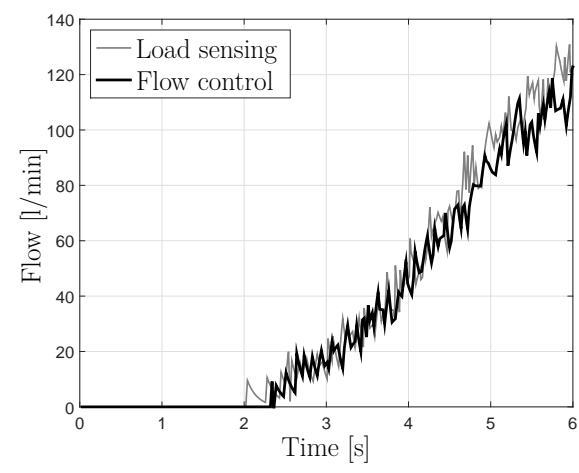

(a) Measured flow for both systems. The flow is increased from zero to maximum.

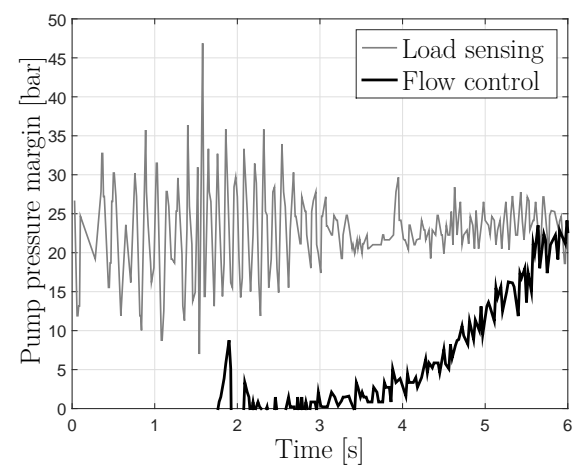

(b) Measured pump pressure margin for both systems while the flow is increased.

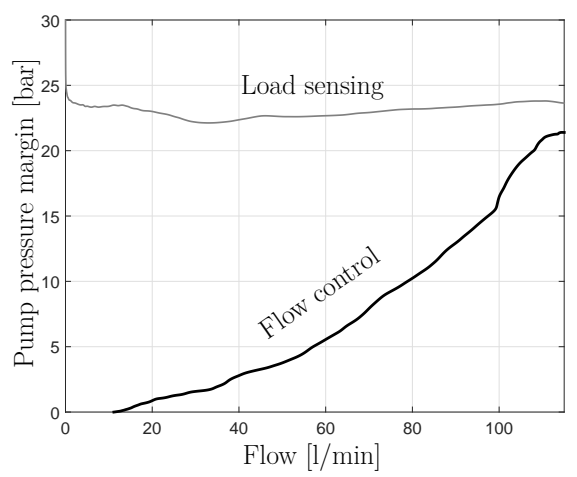

(c) Measured pump pressure margin as a function of measured flow. Load sensing systems have a constant margin while flow control systems have a margin given by the system resistances.

Figure 7.2 Experimental results showing the potential of reducing the pump pressure margin in flow control systems compared to load sensing systems. 


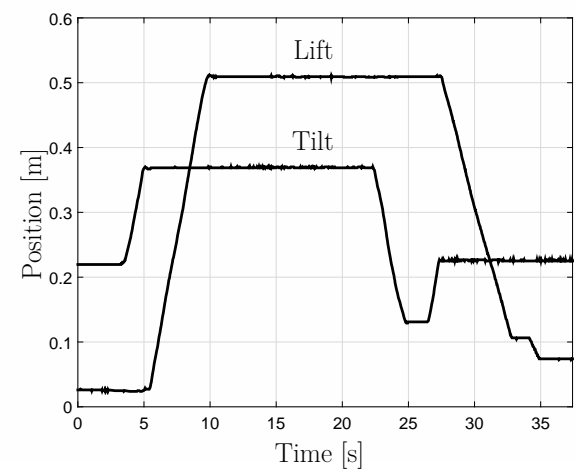

(a) Measured positions of the actuators during the cycle.

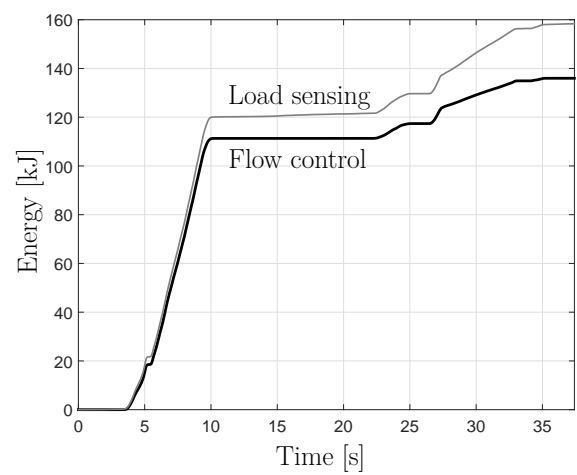

(b) Measured energy consumption during the cycle.

Figure 7.3 Experimental results showing the actuator positions and the consumed energy in a short loading cycle. The flow control system consumed $14 \%$ less energy during the cycle than the load sensing system. 


\subsection{Outlet Orifice Damping Contribution}

A test rig to validate the damping contribution by the outlet orifice has been designed. It consists of a traditional pressure compensated valve on the inlet side, a cylinder with a mass load and a servo valve on the outlet side, see figure 7.4. Different designs of the outlet orifice can be achieved by controlling the opening area of the servo valve. A constant pressure pump supplies the system. Pressure sensors are attached on the supply side and on both cylinder chambers. The cylinder and the servo valve are equipped with position sensors. External volumes are mounted on both sides of the piston. By using either one, it is possible to manipulate the dead volumes on either side of the piston.

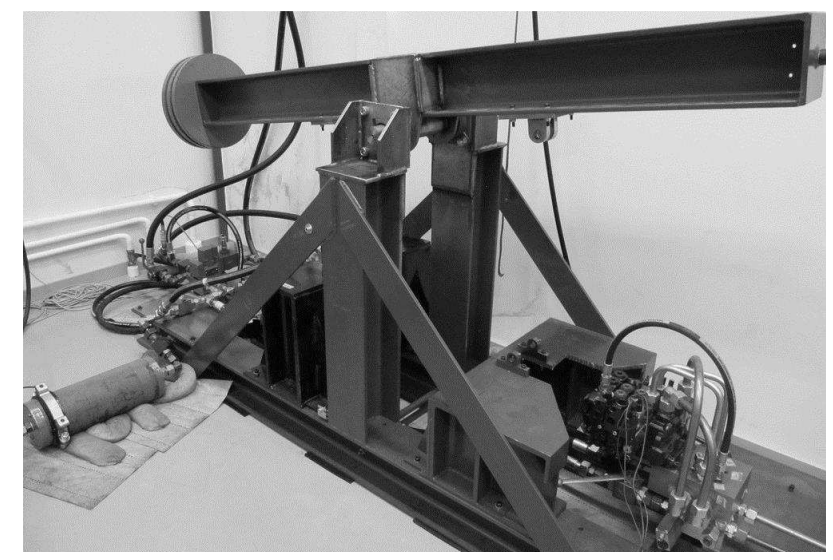

Figure 7.4 The experimental test stand. The pressure compensated valve can be seen at the lower right and one of the volumes to the left.

In the experiments, a step is made in the flow by opening the inlet valve. Oscillations in the cylinder velocity are then studied. The experimental results are presented in figure 7.5. In tests (a) and (b), there is a large volume on the inlet side which means that a relatively high damping can be expected. In test (a), the outlet orifice area is dimensioned close to the maximized damping. As can be seen in figure 7.5a, there are almost no oscillations in the cylinder velocity. In test (b), the outlet orifice area is larger than in test (a) and the damping is reduced, see figure $7.5 \mathrm{~b}$.

In test (c), there is a large volume on the outlet side of the cylinder, which means that the damping is expected to be low. The outlet orifice area is dimensioned close to the maximized damping. Nevertheless, the 
damping is still low according to figure 7.5c. This is consistent with the mathematical analysis according to equations (5.17) and (5.18).

In test (d), the outlet orifice area is so large that it can be equated with having no outlet orifice at all. Theoretically, the hydraulic system will not contribute any damping without an outlet orifice as shown in section 5.3.2. This is almost the case in the measurements, as can be seen in figure $7.5 \mathrm{~d}$. The damping that is still obtained is due to secondary effects ignored in the mathematical analysis, such as friction and leakage.

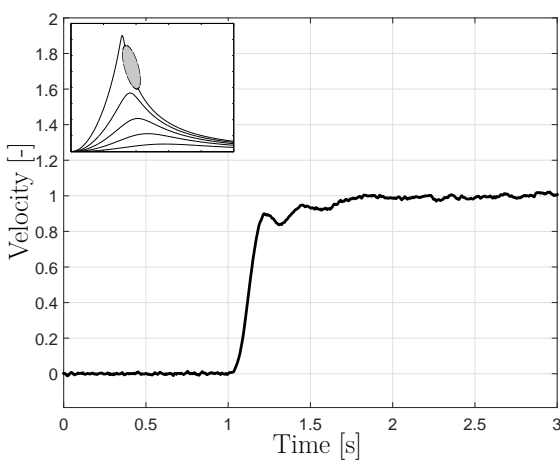

(a) A high damping is obtained when there is a large volume on the inlet side of the cylinder and the outlet orifice is designed close to its optimum.

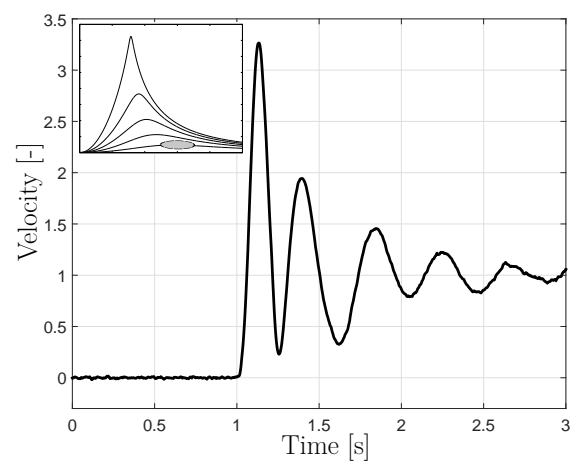

(c) When there is a large volume at the outlet side of the cylinder, the damping is low even if the outlet orifice is designed close to its optimum.

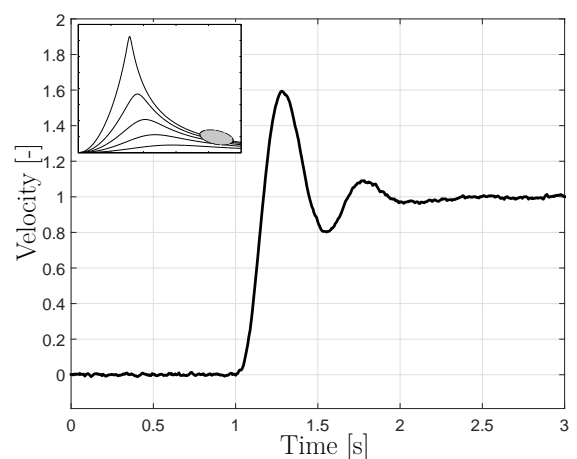

(b) The damping is reduced when there is a large volume at the inlet side and the outlet orifice area is too large.

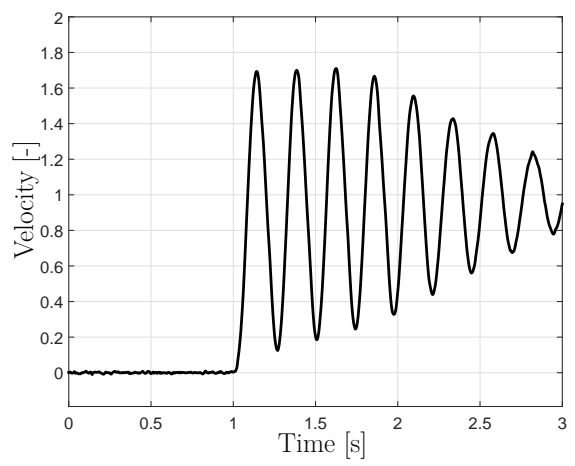

(d) Without an outlet orifice, only secondary effects such as friction and leakage will contribute to the damping.

Figure 7.5 Experimental results for different outlet orifice designs. 


\subsection{Flexible System Characteristics}

A test rig has been designed in order to validate the performance of the flexible working hydraulic system. It is a lorry crane with four actuators: boom, jib, telescope and swing, supplied by an electrically controlled pump that can be operated in both pressure and flow control mode [P1 axial piston pump], see figure 7.6. The closed-centre directional valves are prepared for use with compensators or check valves. Pressure sensors are attached on the supply side, on the load sensing port of the directional valve and on both sides of all cylinders. The cylinders are also equipped with position sensors, a flow sensor is attached on the pump hose, and the pump is equipped with a displacement sensor.

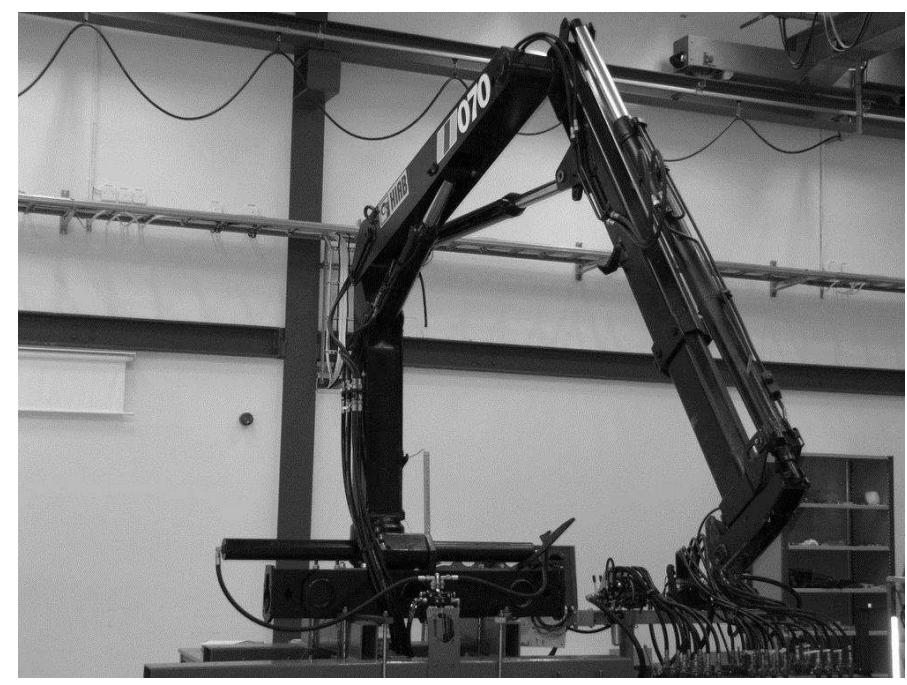

Figure 7.6 The crane used for experiments. The boom cylinder controls the first arm, the jib cylinder controls the second, telescope cylinders can extend the second arm, and the swing cylinders can rotate the crane. The valve packages can be seen lower right.

\subsubsection{Flow Matching Problem}

In this section, it is demonstrated how a combination of pressure and flow control can solve the flow matching problem described in section 3.2.1. The directional valves are equipped with traditional pressure compensators, controlling the absolute flow rate to the loads. The flow command to the pump controller is increased from a correct level to $10 \%$ 
more than the valves are expecting. As can be seen from figure 7.7, the pump pressure margin in flow control mode $(\sigma=0)$ then increases from a level slightly above 10 bar to about 55 bar. Theoretically, the pressure would increase until the system's main relief valve opens but secondary effects such as increased pump leakage stabilize the pressure. By introducing a load pressure feedback into the pump controller, the system will find equilibrium on a lower pressure level. Figure 7.7 shows how $2 \%$ and $5 \%$ load pressure feedback will affect the system. In load sensing mode $(\sigma=1)$, the system is insensitive to an incorrect flow demand since the pump is controlled only by the load pressure feedback.

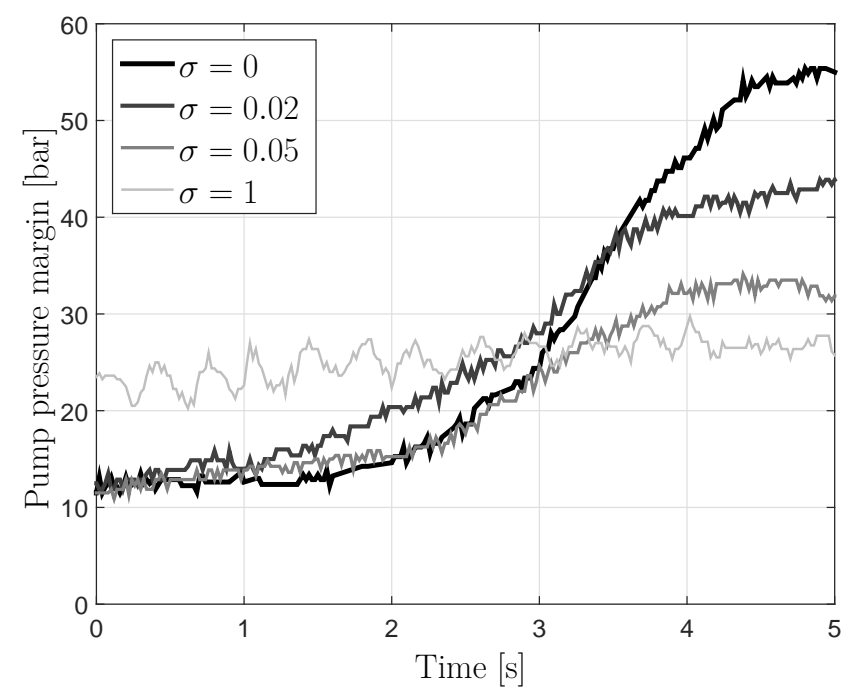

Figure 7.7 Pump pressure margin increase when too much flow is demanded by the pump for different values of $\sigma$. The flow demand is increased from a correct level to $10 \%$ more than the valve expects. A higher value of $\sigma$ will make the pump controller less sensitive to an incorrect flow demand.

\subsubsection{Dynamic Characteristics}

A step is made in the boom function to demonstrate some dynamic differences between load sensing, flow control and solutions in-between. The directional valves are equipped with check valves instead of pressure compensators. It can be seen from figure 7.8 that flow control mode $(\sigma=0)$ gives a faster response than load sensing mode $(\sigma=1)$. This is 
because the chain of signals to the pump controller is shorter. In load sensing mode, the joystick generates a pilot pressure which displaces a directional valve. The highest load pressure can then be sent electrically to the pump controller, which generates flow and thereby a pressure build-up in the pump hose. In flow control mode, a flow demand is sent directly to the pump controller when a joystick is activated. When controlling the pump with a combination of pressure and flow $(\sigma=0.5)$, the response time is between flow control and load sensing.

In figure 7.8 , it is also possible to observe system stability. In load sensing mode, the pump controller is a part of the loop gain, which gives low stability margins and an oscillatory behaviour. By decreasing the value of $\sigma$, and thereby decreasing the loop gain, the pump displacement setting is partly determined by the load pressure feedback signal and partly by the flow command signal. The pressure controller therefore only has to contribute a small part of the total output signal to the displacement control valve, which means that stability margins are gained. The oscillations are therefore lower for $\sigma=0.5$. In flow control mode, the oscillations are similar to $\sigma=0.5$, which means that both systems have high stability margins.

Similar results have also been reported in [Finzel and Helduser, 2008a] where a hydro-mechanical load sensing controller is compared with an electrical flow controller.

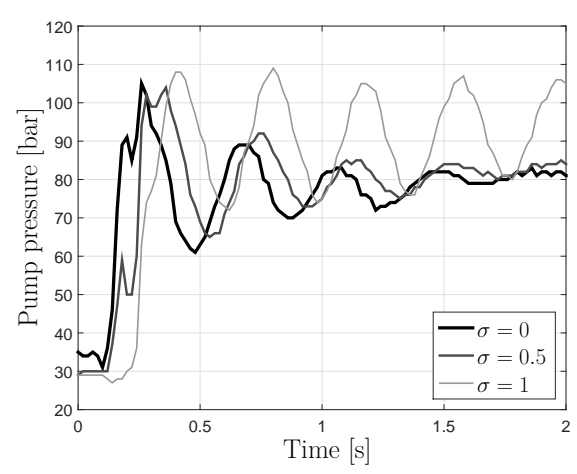

(a) Pump pressure as a function of time.

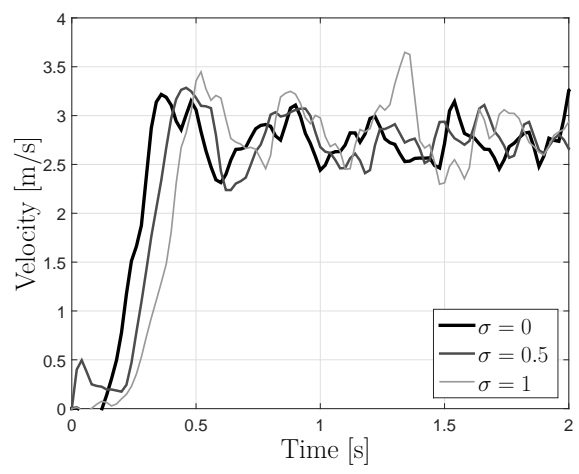

(b) Crane velocity as a function of time.

Figure 7.8 Dynamic comparison of the boom function for different values of $\sigma$. A step is made at 0 seconds. A lower value of $\sigma$ improves the response time and decreases the oscillations. 


\subsubsection{Load Dependency}

This section describes how different levels of load dependency affect the static and dynamic characteristics of the flexible hydraulic system. The pump is in flow control mode $(\sigma=0)$ and the load dependency is set according to $\xi=0,0.5$ and 1 , respectively. The joystick command signal to the jib function is constant and a step is made in the boom function at 1 second. At 4 seconds, the boom joystick signal is set to 0 again. Figures $7.9 \mathrm{a}, 7.9 \mathrm{c}$ and $7.9 \mathrm{e}$ show the pump pressure and the highest load pressure for different levels of load dependency. While moving, the boom function has the highest load pressure. Otherwise, the highest load pressure is the jib function. Figures $7.9 \mathrm{~b}, 7.9 \mathrm{~d}$ and $7.9 \mathrm{f}$ show the boom and jib velocity and also the pump displacement setting.

The pump displacement setting is independent of the load pressure for $\xi=0$. While increasing the value of $\xi$, the flow becomes more pressuredependent. This static difference can be seen in figures $7.9 \mathrm{~b}, 7.9 \mathrm{~d}$ and 7.9f. Since the jib function has a relatively low load pressure, the virtual flow through the open-centre path will be small according to equation (6.1). This results in a higher velocity for the jib function during the first second when increasing the value of $\xi$. When the boom function is actuated, the pressure is increased to a relatively high level, increasing the virtual flow. The boom velocity therefore decreases with a higher value of $\xi$. When the boom stops moving, the pressure is reduced again. Because of the crane geometry, the jib function now requires a slightly higher pressure than between 0 and 1 second. As can be seen from figure $7.9 \mathrm{~b}$, this does not affect the static jib velocity when $\xi=0$. However, when the load dependency is increased, the static jib velocity is slightly lower because of a higher pump pressure, resulting in a higher virtual flow through the open-centre path, see figures $7.9 \mathrm{~d}$ and $7.9 \mathrm{f}$.

The level of load dependency will also affect the dynamic characteristics. When making a step in the boom function at 1 and 4 seconds, the pump displacement setting and the system pressure levels will change. Because of the pump controller dynamics, this results in an overshoot and a few oscillations in the displacement setting when there is no load dependency, see figure 7.9b. When a load dependency exists, oscillations in the pump pressure will affect the pump displacement setting. As the pressure rises, creating an accelerating force, the pump decreases its displacement. The acceleration will then be slowed down, resulting in a 


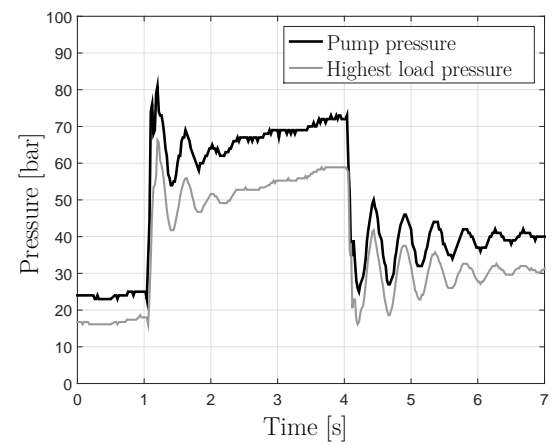

(a) Pressures as a function of time for $\xi=0$.

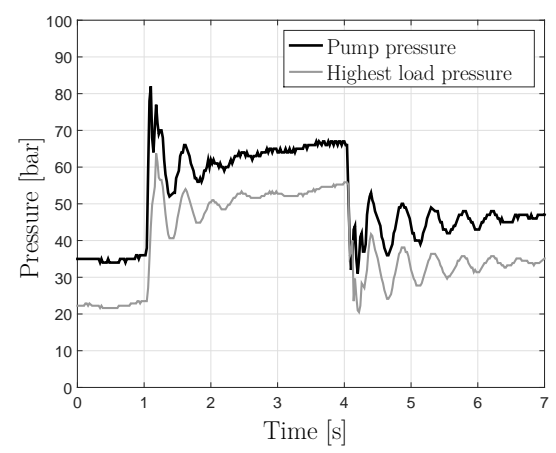

(c) Pressures as a function of time for $\xi=0.5$.

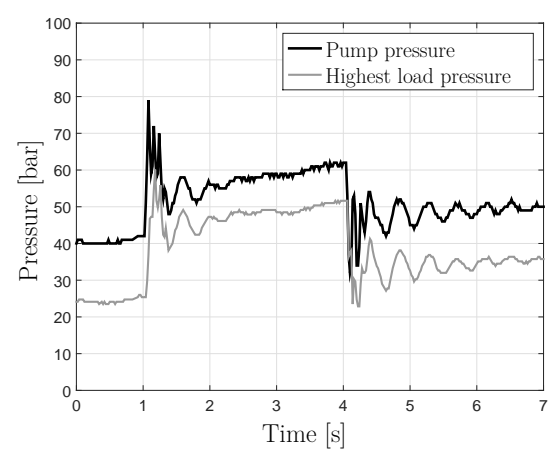

(e) Pressures as a function of time for $\xi=1$.

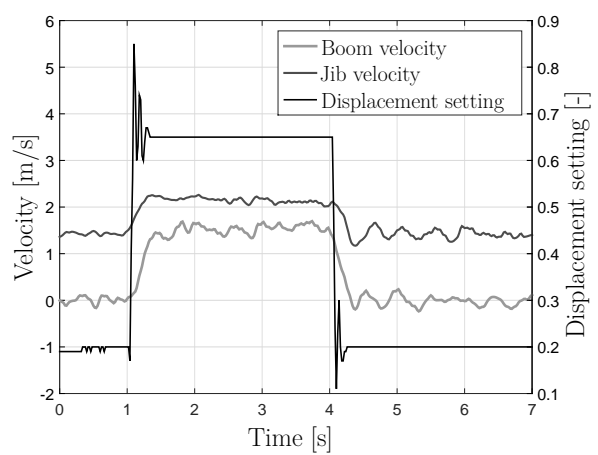

(b) Crane velocity and pump displacement setting as a function of time for $\xi=0$.

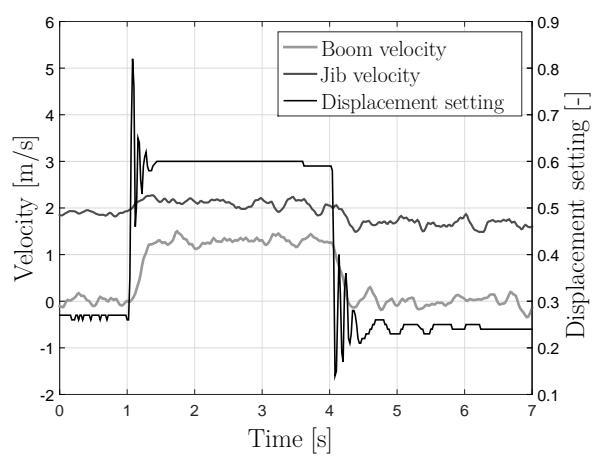

(d) Crane velocity and pump displacement setting as a function of time for $\xi=0.5$.

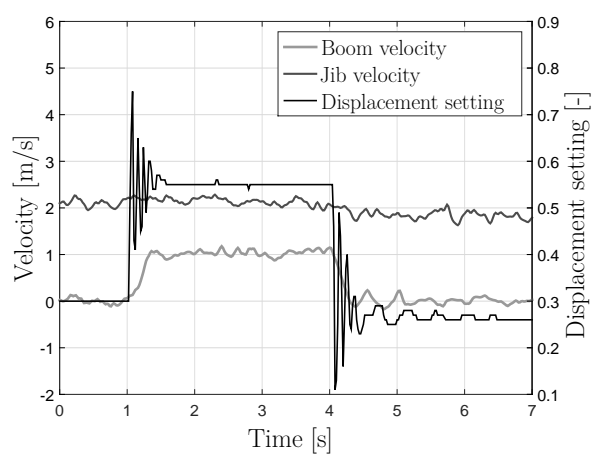

(f) Crane velocity and pump displacement setting as a function of time for $\xi=1$.

Figure 7.9 System characteristics for different values of $\xi$. Decreasing the value of $\xi$ decreases the load dependency. 
system with more damping. As can be seen from figures $7.9 \mathrm{a}, 7.9 \mathrm{c}$ and $7.9 \mathrm{e}$, the pressure oscillations decrease while increasing the load dependency. It can also be seen that the displacement setting is actively controlled in order to reduce the pressure oscillations in figures $7.9 \mathrm{~d}$ and $7.9 f$. 


\section{8 \\ Discussion}

Every working hydraulic system has its own pros and cons and different properties are important in different types of machines and/or working cycles. Table 8.1 summarizes the systems discussed in this thesis in terms of important properties for mobile working hydraulic systems. As can be seen, no system is optimal. Conventional open-centre systems with a fixed displacement pump are a good choice if a simple system with high damping is preferred. Load sensing systems with closed-centre valves improve energy efficiency and velocity control but are poorly damped. Systems with variable displacement pump and open-centre valves are a good compromise but lack the possibility to control velocity. In this thesis, open-centre load sensing, negative load sensing, positive flow control and negative flow control have been discussed. Flow control systems have some benefits compared to closed-centre load sensing but require an electrically controlled pump.

The flexible working hydraulic system proposed in this thesis has high energy efficiency and some adaptable characteristics. It has force control and high damping in open-centre mode and velocity control with low interference in load sensing and flow control mode. It is possible for the operator to tune two different parameters for optimal control characteristics to fit a specific machine, function or working cycle.

When optimizing control characteristics, it is also important to consider the operator. For example, the load sensitivity of an open-centre system is said to give the operator a better feel of the machine. A skilled operator can use this information feedback from the system to advantage and increase the machine's controllability. A non-skilled operator, however, might experience this load dependency as an inconsistency and it 
can then be regarded as a disturbance. With the flexible system layout proposed in this paper, it is possible for each operator to obtain their optimal control characteristics without compromising energy efficiency.

The hardware difference between systems proposed in this thesis and commercially common systems is mainly the pump controller. Conventional hydro-mechanical controllers are well accepted in the market, partly because of their robustness and high bandwidth. Electrohydraulic pump controllers are not yet common commercially but are gaining acceptance. So far, electro-hydraulic controllers cannot compete with hydro-mechanical when it comes to speed and robustness. They are also often sensor-dependent and comparatively expensive. However, electro-hydraulic components have a higher degree of flexibility and give possibilities to introduce more functionality into the software.

One challenge is to keep safety and robustness at an acceptable level while introducing more functionality into the software and complex control algorithms. Furthermore, mobile hydraulic systems entail control difficulties such as nonlinearities, saturation and varying loads. It can, therefore, be beneficial to maintain some critical control functionality in the hardware, for example by using conventional directional valves for simple and precise controllability of the loads. 


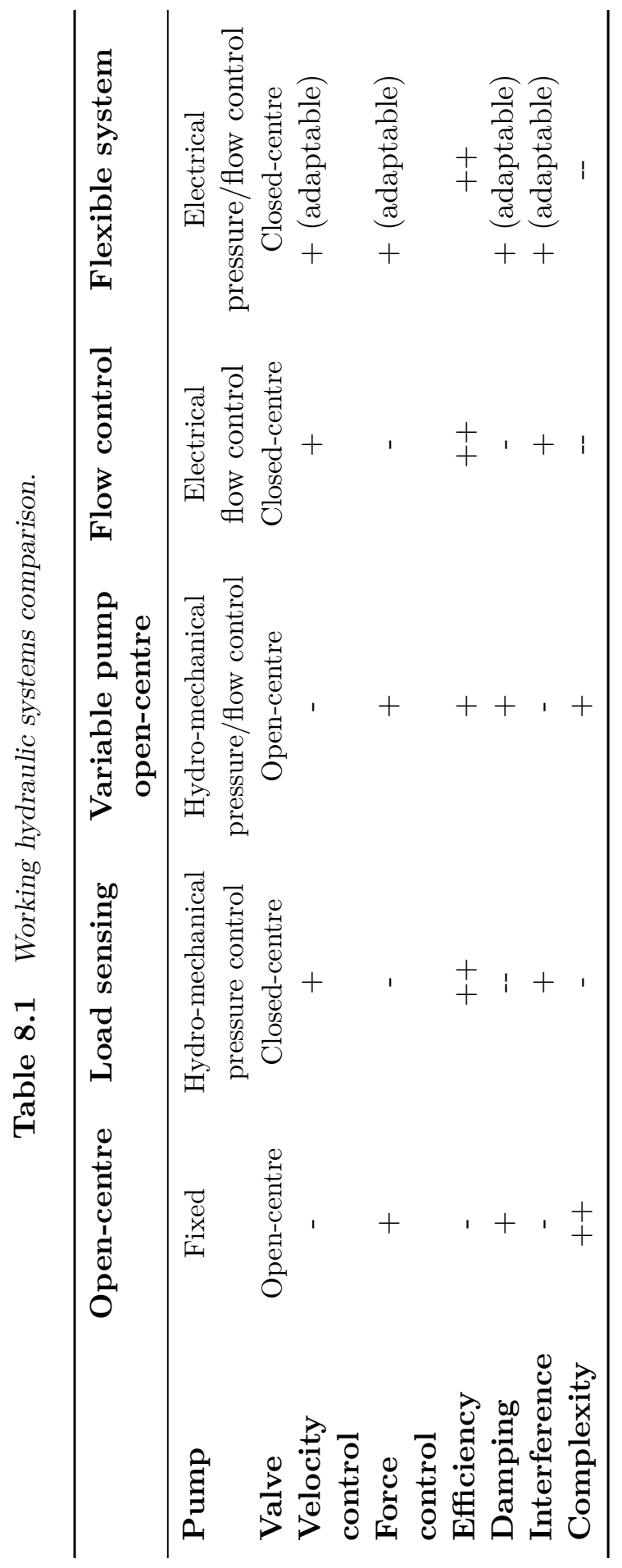




\section{9 \\ Conclusions}

The presented work shows that it is possible to improve dynamic performance and energy efficiency compared to commercially common systems without adding additional components or increasing complexity. A system, referred to as flow control, has been proposed and studied which allows a simpler system design process. This is because the pump interaction with the system dynamics is minimized since there is no need for load sensing feedback. As long as the pump is stable as an isolated component, it will not cause any stability issues in the complete system. In load sensing systems on the other hand, an apparently stable pump can cause instability in the complete system.

Flow control systems are shown to be able to improve energy efficiency compared to load sensing systems. Experiments on a wheel loader application confirm the theoretical expectations and demonstrate energy saving potentials in a short loading cycle. There are also potential energy savings tied to the absence of active control of the pump. Hardware requirements are similar to load sensing except for the need for an electronically controlled pump.

It is also shown how the inlet orifice in directional valves can be actively controlled to optimize damping without affecting actuator velocity. Design rules to obtain high damping from the outlet orifice are proposed and verified by experiments. In some operational cases, however, relatively high energy losses are needed to obtain high damping. This trade-off is investigated and explained.

A novel system architecture is proposed where flow control, load sensing and open-centre are merged into a generalized system description. The proposed system is configurable and by tuning two parameters the 
operator can realize the characteristics of any of the standard systems without compromising energy efficiency. This can be done non-discretely on-the-fly. By controlling the pump with a combination of pressure and flow, it is possible to avoid unnecessary energy losses in case of a flow mismatch between pump and valve, and at the same time improve system response and increase stability margins compared to load sensing. This is verified by experiments. Experiments also demonstrate that the electronically controlled pump is fast enough to satisfy dynamic requirements. 


\section{0 \\ Outlook}

Today, both academia and industry devote a great deal of effort to the area of energy-efficient hydraulic systems. This will most likely continue in the future. In the short term, flow control systems are a complement, or alternative, to load sensing systems in particular applications. The challenge is how, and to what extent, sensors should be used. It is possible to design a flow control system without the need for sensors, but it might be desirable to use sensors in some operational cases. One example is when a cylinder reaches its end stop. From an efficiency point of view, substantial power savings are possible if the pump controller has such information feedback from the loads.

In the longer term, individual metering and valveless systems will probably gain market shares. Those systems are more energy-efficient, especially during partial loading conditions. Furthermore, they also have the possibility to recuperate energy from the loads. This energy can either be used to run the system pump as a motor or be stored in, for example, an accumulator. One interesting system layout in the future could be to use a fixed displacement bidirectional pump powered by an electric motor in flow control systems. This is a hybrid of EHA and flow control.

Which hydraulic system to choose will always be a compromise between, for example, efficiency, static and dynamic characteristics, controllability, complexity, space requirements and cost. The flexible hydraulic system design proposed in this thesis might be an alternative in the future to avoid some of these compromises.

Pure electrical functions will probably take market shares from hydraulics in the future. For example, there are already electrical drive- 
lines available and their performance can be expected to improve. At the same time, electrical components are likely to become cheaper. The field of hydraulics will, however, probably have its niche in high power applications and linear movements of large forces also in the future. 


\section{1}

\section{Review of Papers}

In this chapter, the six appended papers in this thesis are briefly summarized. Papers I and II analyse different aspects of flow control systems and compare the findings with load sensing systems. The damping contribution of the outlet orifice is studied in paper III. In paper IV, a combination of flow control and load sensing is proposed. Paper V proposes a flow control solution with open-centre characteristics. In paper VI, the findings from papers IV and V are put together, creating an energy-efficient and flexible working hydraulic system.

\section{Paper I}

\section{Flow versus pressure control of pumps in mobile hydraulic sys- tems}

This paper makes a review of both commercially available and future working hydraulic systems for mobile machines. The flow control concept is introduced and different pressure compensator techniques are studied. The flow matching problem when using traditional compensators in combination with a flow controlled pump is exemplified. Solutions with flow sharing compensators are presented, which include a control strategy where the directional valve with the highest flow demand can be fully opened with the aim of saving energy. Flow control and load sensing are compared in terms of energy efficiency and dynamics characteristics. Simulation results are shown and verified by experiments in a wheel loader application. The results show increased energy efficiency in flow control systems compared to load sensing systems. 


\section{Paper II}

\section{Dynamic Analysis of Single Pump, Flow Controlled Mobile Sys- tems}

In this paper, a dynamic analysis is performed where load sensing and flow control systems are compared. Different pressure compensators are included. It is shown that instability might occur in load sensing systems due to the load pressure feedback to the pump controller and proven that no such instability properties are present in flow control systems. It is mathematically shown that flow sharing compensators will dynamically disturb lighter loads. A novel way of controlling the directional valve in order to optimize the damping is proposed. This can be done without affecting the cylinder velocities. A relatively high pressure drop across the inlet orifice in the directional valve is often required to obtain a high damping.

\section{Paper III}

\section{Optimized Damping in Cylinder Drives Using the Meter-out Orifice - Design and Experimental Verification}

This paper analyses the damping contribution given by the outlet orifice in the directional valve. The analysis is not limited to flow control systems but is valid for all pump controller designs. The requirement is that there is no flow-pressure dependency at the inlet side of the valve, which can be realized with for example a traditional pressure compensator. There is an optimal orifice area to obtain the highest possible damping. Both smaller and larger areas give lower damping. A valve design is proposed which optimizes the damping in the worst case scenario. Experimental results confirming the theoretical expectations are also presented.

\section{Paper IV}

\section{A Hybrid of Pressure and Flow Control in Mobile Hydraulic Systems}

In this paper, a hybrid pump controller influenced by both pressure and flow is proposed. The controller is tuneable to be able to set the order 
of importance of the pressure and the flow controller, respectively. It is thus possible to realize a load sensing system, a flow control system or a mix of the two. Using a low load pressure feedback gain and a high flow control gain, a system emerges with high energy efficiency, fast system response, high stability margins and no flow matching issues. Both theoretical studies and practical implementations demonstrate the capability of a hybrid pump control approach.

\section{Paper V}

\section{Energy Efficient Fluid Power System for Mobile Machines with Open-centre Characteristics}

This paper presents a flexible and energy-efficient system solution which mimics the behaviour of an open-centre system. Instead of having a flow in the open-centre gallery, that flow is calculated using a pressure sensor and a valve model. The variable pump is then controlled in order to only deliver the flow that would go to the actual loads. It is also possible for the operator to decide how much load dependency there should be. It is possible to realize a system design with open-centre characteristics, a flow control system or something in-between. Each operator can thereby have their optimal control characteristics with high energy efficiency. A dynamic analysis and simulation results are presented.

\section{Paper VI}

\section{A Flexible Working Hydraulic System for Mobile Machines}

In this paper, the findings from papers IV and V are put together, creating an energy-efficient and flexible working hydraulic system. It is possible to realize open-centre, load sensing and flow control, but also a mix of the three systems. One electrically controlled variable displacement pump supplies the system and conventional closed-centre spool valves are used. The pump control strategies are explained in detail. The operator has the possibility to set two different parameters, which results in different static and dynamic system characteristics. Experimental results demonstrating one solution to the flow matching problem and the static and dynamic differences between different control modes are presented. 
Mobile Working Hydraulic System Dynamics 


\section{Bibliography}

Achten, P., Z. Fu, and G. Vael (1997). "Transforming future hydraulics: a new design of a hydraulic transformer". In: The 5th Scandinavian International Conference on Fluid Power (SICFP'97). Linköping, Sweden.

Achten, P., G. Vael, T. van den Brink, J. Potma, and M. Schellekens (2011). "Efficiency measurements of the Hydrid motor/pump". In: The Twelfth Scandinavian International Conference on Fluid Power (SICFP'11). Vol. 3. Tampere, Finland, pp. 41-49.

Andersson, B.R. (1980). "A Survey of Load-Sensing Systems". In: The BFPR Journal 13, pp. 103-115.

Andersson, B.R. (1997). "Valves Contribution to System Damping". In: The 5th Scandinavian International Conference on Fluid Power (SICFP'97). Linköping, Sweden.

Andersson, B.R. (2013). "3G - the third generation of mobile valves". In: The 13th Scandinavian International Conference on Fluid Power (SICFP2013). Linköping, Sweden.

Bosch Rexroth. Flow sharing control block in mono block/sandwich plate design M6-15. Data Sheet RE 64321.

Bosch Rexroth. Virtual Bleed Off VBO. www.boschrexroth.com/vbo.

Brand, M. (2012). "More Functionality with Electronification - Today and Tomorrow". In: Mobile. Ulm.

Cheng, M., B. Xu, W. Liu, and H. Yang (2013). "Study on the electrohydraulic flow matching control system with a bypass unloading valve". In: Proceedings of the 8th International Conference on Fluid Power Transmission and Control (ICFP). Hangzhou, China, pp. 208212. 
Cheng, M., B. Xu, and H. Yang (2014). "Efficiency Improvement for Electrohydraulic Flow Sharing Systems". In: 9th International Fluid Power Conference (IFK). Vol. 1. Aachen, Germany, pp. 202-211.

Choeng, H. K. (2011). "Negative control type hydraulic system". Patent EP2341193 A2 (Volvo Construction Equipment).

Cobo, M., R. Ingram, E. Reiners, and M. Vande Wiele (1999). "Positive flow control system". Patent US5873244 A (Caterpillar).

Dengler, P., M. Geimer, H. Baum, G. Schuster, and C. Wessing (2012). "Efficiency Improvement of a Constant Pressure System using an Intermediate Pressure Line". In: 8th International Fluid Power Conference (IFK). Vol. 1. Dresden, Germany, pp. 567-578.

Djurovic, M. (2007). "Energiesparende Antriebssysteme für die Arbeitshydraulik mobiler Arbeitsmaschinen "Elektrohydraulisches Flow Matching"'. PhD thesis. Institut für Fluidtechnik der Technischen Universität Dresden.

Djurovic, M. and S. Helduser (2004). "New control strategies for electrohydraulic load-sensing". In: Fluid Power and Motion Control (FPMC). Bath, UK, pp. 201-210.

Djurovic, M., S. Helduser, and G. Keuper (2004). "Neue Lösungen zum elektrohydraulischen Load-Sensing". In: 4th International Fluid Power Conference (IFK). Vol. 2. Dresden, Germany, pp. 59-70.

Djurovic, M., G. Keuper, and P. Stachnik (2006). "Intelligentes Ölmanagement mit: EFM: Applikation und Potentiale des elektrohydraulischen Flow-Matching am Beispiel Traktor". In: 4. Kolloquium Mobilhydraulik, Braunschweig.

Eriksson, B. (2007). "Control Strategy for Energy Efficient Fluid Power Actuators - Utilizing Individual Metering". Licentiate thesis. Linköping University.

Eriksson, B. (2010). "Mobile Fluid Power Systems Design - with a Focus on Energy Efficiency". PhD thesis. Linköping University.

Eriksson, B. and J.-O. Palmberg (2010). "How to Handle Auxiliary Functions in Energy Efficient, Single Pump, Flow Sharing Mobile Systems". In: The 7th International Fluid Power Conference (IFK). Aachen, Germany.

Eriksson, B. and J.-O. Palmberg (2011). "Individual Metering Fluid Power Systems: Challenges and Opportunities". In: Proceedings of the Institution of Mechanical Engineers, Part I: Journal of Systems and Control Engineering 225, pp. 196-211. 
Fedde, T. and H.-H. Harms (2006). "An adaptive hydraulic system for mobile applications". In: The 5th International Fluid Power Conference (IFK). Vol. 3. Aachen, Germany, pp. 95-106.

Filla, R. (2011). "Quantifying Operability of Working Machines". PhD thesis. Linköping University.

Filla, R. (2014). "Method for controlling a hydraulic system". Patent US8751114 B2 (Volvo Construction Equipment).

Finzel, R. (2010). "Elektrohydraulische Steuerungssysteme für mobile Arbeitsmaschinen". PhD thesis. Institut für Fluidtechnik der Technischen Universität Dresden.

Finzel, R. and S. Helduser (2008a). "Energy-Efficient Electro-Hydraulic Control Systems for Mobile Machinery / Flow Matching". In: 6th International Fluid Power Conference. Vol. 1. Dresden, Germany, pp. 89-102.

Finzel, R. and S. Helduser (2008b). "New Electro-Hydraulic Control Systems for Mobile Machinery". In: Fluid Power and Motion Control (FPMC). Bath, UK, pp. 309-321.

Finzel, R., S. Helduser, and D.-S. Jang (2009). "Electro-hydraulic control systems for mobile machinery with low energy consumption". In: Proceedings of the Seventh International Conference on Fluid Power Transmission and Control (ICFP). Hangzhou, China, pp. 214-219.

Finzel, R., S. Helduser, and D.-S. Jang (2010). "Electro-Hydraulic DualCircuit System to Improve the Energy Efficiency of Mobile Machines". In: 7th International Fluid Power Conference (IFK). Aachen, Germany.

Gomm, R. and D. Vanderlaan (2009). "Velocity control of unbalanced hydraulic actuator subjected to over-center load conditions". Patent EP2318720 B1 (Parker-Hannifin).

Grey, C.L. (2011). "Is the Hydraulics Industry Ready for A World Desperate for Affordable Transportation?" In: 2011 IFPE Conference.

Grösbrink, B., T. von Baumgarten, and H.-H. Harms (2010). "Alternating Pump Control for a Load-Sensing System". In: 7th International Fluid Power Conference (IFK). Aachen, Germany.

Grösbrink, B. and H.-H. Harms (2009). "Control concept for an advanced load-sensing system". In: 7th International Conference on Fluid Power Transmission and Control. Hangzhou, China.

Hansen, R. (2009). "Advanced Power Management of a Telehandler using Electronic Load Sensing". In: 10th International Workshop on Research and Education in Mechatronics. Glasgow, UK. 
Hansen, R., T. Andersen, and H. Pedersen (2010). "Development and Implementation of an Advanced Power Management Algorithm for Electronic Load Sensing on a Telehandler". In: Fluid Power and Motion Control (FPMC). Bath, UK, pp. 537-550.

Heybroek, K. (2008). "Saving Energy in Construction Machinery using Displacement Control Hydraulics - Concept Realization and Validation". Licentiate thesis. Linköping University.

Inderelst, M. (2013). "Efficiency improvements in mobile hydraulic systems". PhD thesis. Technische Hochschule Aachen.

Johansson, L.-G. (2003). Introduktion till vetenskapsteorin. Bokförlaget Thales.

Jongebloed, H., D. van Büren, U. Völkel, and C. Jabs (2004). "EnergySaving Valve System for Mobile Applications - Load-Control-System (LCS)". In: 4th International Fluid Power Conference (IFK). Dresden, Germany, pp. 117-128.

Kawasaki Precision Machinery. Swash-plate Axial Piston Pump B Series K3VL. Data Sheet P-1002/04.11 GB.

Krus, P. (1988). "On Load Sensing Fluid Power Systems - With Special Reference to Dynamic Properties and Control Aspects". PhD thesis. Linköping University.

Lantto, B. (1994). "On Fluid Power Control with Special Reference to Load-Sensing Systems and Sliding Mode Control". PhD thesis. Linköping University.

Latour, C. (2006). "Electrohydraulic Flow Matching (EFM) - The next Generation of Load Sensing Controls". In: Mobile. Ulm.

Liao, W., S. Chen, C. Chen, H. Du, F. Wang, and N. Zhao (2012). "Research of Negative Flow Control Characteristics for Axial Piston Pump Based on Hydraulic and Mechanical Co-simulation". In: 3rd International Conference on System Science, Engineering Design and Manufacturing Informatization. Chengdu, China.

Merritt, H.E. (1967). Hydraulic Control Systems. John Wiley \& Sons, Inc.

Mettälä, K., M. Djurovic, G. Keuper, and P. Stachnik (2007). "Intelligent Oil Flow Management with EFM: The Potentials of Electrohydraulic Flow Matching in Tractor Hydraulics". In: The Tenth Scandinavian International Conference on Fluid Power (SICFP'07). Vol. 3. Tampere, Finland, pp. 25-34. 
Murrenhoff, H., S. Sgro, and M. Vukovic (2014). "An Overview of Energy Saving Architectures for Mobile Applications". In: 9th International Fluid Power Conference (IFK). Vol. 2. Aachen, Germany.

Paavilainen, H., J. Savolainen, and J. Kullaa (2007). "Vibration Damping of the Crane". In: The 10th Scandinavian International Conference on Fluid Power (SICFP). Tampere, Finland.

Palmberg, J.-O., P. Krus, and D. Kangzhi (1985). "Dynamic Response Characteristics of Pressure Control Pumps". In: First International Conference on Fluid Power Transmission and Control (ICFP). Hangzhou, China.

Palmgren, G. (1988). "On Secondary Controlled Hydraulic Systems". Licentiate thesis. Linköping University.

Parker Hannifin. L90LS Mobile Directional Control Valve - Proportional, Load Sensing, Pre-compensated. Catalogue HY17-8504/UK.

Parker Hannifin. P1/PD Series Medium Pressure Axial Piston Pumps Variable Displacement. Catalogue HY28-2665-01/P1/EN.

Pettersson, H., P. Krus, A. Jansson, and J.-O. Palmberg (1996). "The Design of Pressure Compensators for Load Sensing Hydraulic Systems". In: UKACC International Conference on Control'96. Southampton.

Rahmfeld, R. and M. Ivantysynova (2001). "Displacement controlled linear actuator with differential cylinder - a way to save primary energy in mobile machines". In: Fifth International Conference on Fluid Power Transmission and Control (ICFP). Vol. 1. Hangzhou, China, pp. 316-322.

Rahmfeld, R. and M. Ivantysynova (2004). "An Overview About Active Oscillation Damping of Mobile Machine Structure". In: International Journal of Fluid Power 5.2, pp. 5-24.

Rahmfeld, R., M. Ivantysynova, and J. Weber (2004). "Displacement Controlled Wheel Loader - a simple and clever Solution". In: 4th International Fluid Power Conference (IFK). Vol. 2. Dresden, Germany, pp. 183-196.

Raymond, E.T. and C.C. Chenoweth (1993). Aircraft Flight Control Actuation System Design. Society of Automotive Engineers.

Rydberg, K.-E. (2009). "Energy Efficient Hydraulic Hybrid Drives". In: The 11th Scandinavian International Conference on Fluid Power (SICFP'09). Linköping, Sweden.

Scherer, M. (2015). "Beitrag zur Effizienzsteigerung mobiler Arbeitsmaschinen - Entwicklung einer elektrohydraulischen Bedarfsstroms- 
teuerung mit aufgeprägtem Volumenstrom". PhD thesis. Karlsruher Institut für Technologie.

Scherer, M., M. Geimer, and B. Weiss (2013a). "Contribution on Control Strategies of Flow-On-Demand Hydraulic Circuits". In: The 13th Scandinavian International Conference on Fluid Power (SICFP2013). Linköping, Sweden.

Scherer, M., M. Geimer, and B. Weiss (2013b). "Forestry Crane with Electrohydraulic Flow-on-Demand System". In: Proceedings of the 71th Landtechnik - AgEng. Hannover, pp. 175-182.

Stenlund, S. (1988). "Electrohydraulic guide system". Patent EP0417087 A1.

Thiebes, P. (2011). "Hybridantriebe für mobile Arbeitsmaschinen". PhD thesis. Karlsruher Institut für Technologie.

Vael, G., P. Achten, and T. van den Brink (2009). "Efficiency of a Variable Displacement Open Circuit Floating Cup Pump". In: The 11th Scandinavian International Conference on Fluid Power (SICFP'09). Linköping, Sweden.

Weber, J. and W. Burget (2012). "Mobile Systems - Markets, Industrial Needs and Technological Trends". In: 8th International Fluid Power Conference (IFK). Vol. 2. Dresden, Germany, pp. 23-54.

Werndin, R. and J.-O. Palmberg (2003). "Hydraulic transformers - comparison of different designs". In: The Eighth Scandinavian International Conference of Fluid Power (SICFP'03). Tampere, Finland.

Williamson, C. and M. Ivantysynova (2007). "The effect of pump efficiency on displacement-controlled actuator systems". In: The Tenth Scandinavian International Conference on Fluid Power (SICFP'07). Tampere, Finland.

Wu, D., R. Burton, G. Schoenau, and D. Bitner (2007). "Analysis of a Pressure-Compensated Flow Control Valve". In: Journal of Dynamic Systems, Measurement, and Control 129, pp. 203-211.

Xu, B., M. Cheng, H. Yang, J. Zhang, and C. Sun (2015). "A Hybrid Displacement/Pressure Control Scheme for an Electrohydraulic Flow Matching System". In: IEEE/ASME Transactions on Mechatronics PP, pp. 1-12.

Xu, B., W. Liu, M. Cheng, and H. Yang (2012). "A new Electrohydraulic Load Sensing Control System for Hydraulic Excavators". In: 8th International Fluid Power Conference (IFK). Vol. 1. Dresden, Germany, pp. 553-565. 
Yuan, H., M. Vukovic, Y. Shang, S. Wu, H. Murrenhoff, and Z. Jiao (2014). "Characteristics of Energy Efficient Switched Hydraulic Systems". In: 9th JFPS International Symposium on Fluid Power. Matsue, Japan, pp. 51-58.

Zähe, B. (1993). "Energiesparende Schaltungen hydraulischer Antriebe mit veränderlichem Versorgungsdruck und ihre Regelung". PhD thesis. Rheinisch-Westfälische Technische Hochschule Aachen. 


\section{Papers}

The articles associated with this thesis have been removed for copyright reasons. For more details about these see:

http://urn.kb.se/resolve?urn=urn:nbn:se:liu:diva-121070 